\title{
Guia de identificação das espécies de Scarabaeinae (Coleoptera: Scarabaeidae) do município de Santa Maria, Rio Grande do Sul, Brasil
}

\author{
Pedro Giovâni da Silva ${ }^{1,2,4}$, Fernando Zagury Vaz-de-Mello ${ }^{3}$ \& Rocco Alfredo Di Mare ${ }^{1}$ \\ ${ }^{1}$ Programa de Pós-graduação em Biodiversidade Animal, Universidade Federal de Santa Maria - UFSM, \\ Av. Roraima, 1000, Camobi, CEP 97105-900, Santa Maria, RS, Brasil \\ ${ }_{2}^{2}$ Programa de Pós-graduação em Ecologia, Universidade Federal de Santa Catarina - UFSC, \\ CEP 88040-970, Florianópolis, SC, Brasil \\ ${ }^{3}$ Departamento de Biologia e Zoologia, Instituto de Biociências, Universidade Federal de Mato Grosso - UFMT, \\ Av. Fernando Corrêa da Costa, 2367, Boa Esperança, CEP 78060-900, Cuiabá, MT, Brasil \\ ${ }^{4}$ Autor para correspondência: Pedro Giovâni da Silva, e-mail: pedrogiovanidasilva@yahoo.com.br
}

SILVA, P.G., VAZ-DE-MELLO, F.Z. \& DI MARE R.A. Identification handbook of the Scarabaeinae species (Coleoptera: Scarabaeidae) of the city of Santa Maria, Rio Grande do Sul, Brazil. Biota Neotrop. 11(4): http://www.biotaneotropica.org.br/v11n4/en/abstract?article+bn03411042011

\begin{abstract}
Here is presented a guide to identify the species of Scarabaeinae occurring in Santa Maria, Rio Grande do Sul, compiled from the literature and captured between May 2009 and April 2010 in forest fragments. A dichotomous key, characterization, illustrations (species collected) and ecological information for 35 species are provided.

Keywords: dung beetle, Scarabaeoidea, dichotomous key, systematics, Atlantic Forest.

SILVA, P.G., VAZ-DE-MELLO, F.Z. \& DI MARE R.A. Guia de identificação das espécies de Scarabaeinae (Coleoptera: Scarabaeidae) do município de Santa Maria, Rio Grande do Sul, Brasil. Biota Neotrop. 11(4): http://www.biotaneotropica.org.br/v11n4/pt/abstract?article+bn03411042011

Resumo: Apresenta-se um guia de identificação das espécies de Scarabaeinae ocorrentes em Santa Maria, Rio Grande do Sul, arroladas da literatura e capturadas entre maio de 2009 a abril de 2010 em fragmentos florestais. São fornecidas chave dicotômica, caracterização, ilustrações (das espécies coletadas) e informações ecológicas para 35 espécies.

Palavras-chave: rola-bosta, Scarabaeoidea, chave dicotômica, sistemática, Mata Atlântica.
\end{abstract}




\section{Introdução}

Os insetos pertencentes à subfamília Scarabaeinae (Coleoptera: Scarabaeidae) são componentes importantes dos ecossistemas naturais e agropecuários, pois realizam inúmeras funções ecológicas benéficas ao ambiente, as quais são negativamente afetadas pela atividade humana e perturbação do habitat (Halffter \& Matthews 1966, Halffter \& Edmonds 1982, Hanski \& Cambefort 1991, Halffter 1991, Nichols et al. 2008). A alta sensibilidade deste grupo às transformações ambientais faz dele um importante indicador para o monitoramento dos ecossistemas, uma vez que apresenta características satisfatórias para esta finalidade (Halffter \& Favila 1993, Favila \& Halffter 1997, Davis et al. 2004, Spector 2006).

Scarabaeinae apresenta mundialmente cerca de 7000 espécies (Schoolmeesters et al. 2010), sendo a maior diversidade concentrada em florestas e savanas na faixa tropical (Halffter \& Matthews 1966, Hanski \& Cambefort 1991), havendo grande relação da distribuição deste grupo com o clima e a diversidade de mamíferos (Davis et al. 2002). A maioria das espécies utiliza excrementos, carcaças e frutas podres como recurso alimentar tanto na fase adulta quanto na larval (Halffter \& Matthews 1966).

Na região Neotropical a fauna de Scarabaeinae é muito diversa nas florestas tropicais (Gill 1991, Halffter 1991), onde o Brasil possui a maior riqueza de Scarabaeinae: 618 espécies registradas até o ano de 2000 (Vaz-de-Mello 2000). Contudo, espécies foram descritas e grupos revisados, e a realização de novos levantamentos em regiões ainda não bem inventariadas poderá praticamente dobrar este número (Vaz-de-Mello 2000).

Para o Rio Grande do Sul foram citadas 79 espécies de Scarabaeinae, sendo cinco endêmicas (Vaz-de-Mello 2000). A maioria dos dados sobre os Scarabaeinae do estado provém de bibliografias antigas de descrição e estudo de séries de espécies depositadas em coleções científicas. Recentemente, alguns estudos direcionados ao grupo foram realizados na região da Campanha do estado, inserida no Bioma Pampa (Audino 2007, Silva et al. 2008, 2009, Audino et al. 2011, Silva 2011). Entretanto, somente a continuidade de levantamentos nas demais regiões poderá diminuir a falta de conhecimento das espécies de Scarabaeinae que ocorrem no Rio Grande do Sul, podendo vir a ampliar a distribuição no território brasileiro.

Dessa forma, o objetivo é auxiliar na identificação das espécies de Scarabaeinae do município de Santa Maria, Rio Grande do Sul, com a elaboração de uma chave dicotômica preliminar contendo imagens de caracteres e das espécies capturadas.

A amostragem das espécies foi realizada em três fragmentos florestais com o uso de armadilhas de queda iscadas com excremento humano, carne apodrecida e banana fermentada, entre maio de 2009 e abril de 2010. Os espécimes encontram-se depositados nas coleções do Laboratório de Biologia Evolutiva da Universidade Federal de Santa Maria e do Instituto de Biociências da Universidade Federal de Mato Grosso.

\section{Características de Scarabaeinae}

No Brasil, os representantes de Scarabaeinae são popularmente conhecidos como "rola-bostas" devido ao comportamento que várias espécies possuem de rodar e enterrar no solo porções de alimento (excremento, carcaça ou fruta podre) em forma de esfera, comportamento chamado de telecoprismo. Além deste, há outro grupo que leva porções de alimento para pequenos túneis construídos ao redor ou logo abaixo do alimento, comportamento conhecido como paracoprismo. Outro pequeno conjunto de espécies se alimenta e constrói seus ninhos no interior do alimento, comportamento chamado de endocoprismo. Estas são as três principais guildas comportamentais presente na maioria dos escarabeíneos (Halffter \& Matthews 1966, Cambefort \& Hanski 1991).

Contudo, estes comportamentos podem apresentar variações e mesmo adaptações, sendo subdivididos em várias outras categorias (Halffter \& Edmonds 1982). Existem ainda, espécies que não se enquadram nestas guildas e apresentam comportamento compatível com o substrato utilizado na alimentação e nidificação (Pereira \& Martínez 1956, Halffter \& Matthews 1966, Matthews 1972, Halffter 1977, Cook 1998, Herrera et al. 2002, Vaz-de-Mello 2007a, Jacobs et al. 2008). Algumas espécies podem também se alimentar de outros recursos como, por exemplo, fungos (Halffter \& Matthews 1966, Navarrete-Heredia \& Galindo-Miranda 1997, Falqueto et al. 2005) e ovos em decomposição (Louzada \& Vaz-de-Mello 1997, Pfrommer \& Krell 2004).

Devido à alta especialização do grupo na coprofagia, Scarabaeinae é muito frequente em pastagens naturais ou introduzidas em agroecossistemas pecuários (Silva et al. 2007, Koller et al. 2007, Louzada \& Silva 2009), onde as espécies contribuem com o combate a parasitos, como dípteros e nematódeos que se desenvolvem nas massas fecais (Ridsdill-Smith \& Hayles 1990), além de incorporar material orgânico ao solo, auxiliar na aeração e hidratação edáfica através da construção de suas galerias, e na reciclagem de nutrientes (Milhomem et al. 2003, Bang et al. 2005, Nichols et al. 2008).

Neste sentido, o Centro Nacional de Pesquisa de Gado de Corte (Embrapa - CNPGC) de Mato Grosso do Sul, introduziu no Brasil a espécie africana de Scarabaeinae, Digitonthophagus gazella (Fabricius, 1787), para acelerar a decomposição de massas fecais e combater a mosca-dos-chifres (Haematobia irritans irritans [Linnaeus, 1758]) (Miranda et al. 1990). Esta espécie é coprófaga de fezes bovinas e de outros grandes herbívoros (Rougon \& Rougon 1980, Silva \& Vidal 2007), possui ciclo de vida curto (cerca de um mês) (Koller et al. 2007) e pode deixar até 80 descendentes por geração (Honer et al. 1992), uma aparente vantagem no potencial de enterrar massas fecais em relação às espécies nativas, as quais são consideradas menos eficientes na remoção de excremento bovino (Koller et al. 2006, 2007).

A maior parte do grupo é facilmente amostrada através de armadilhas de queda iscadas com os recursos de que se alimenta (Lobo et al. 1988, Halffter \& Favila 1993). Também podem ser utilizadas armadilhas de interceptação de voo (Spector 2006, Costa et al. 2009), especialmente para as espécies que possuem hábito alimentar pouco comum, e armadilhas luminosas, para a captura de algumas espécies de hábitos noturnos que são facilmente atraídas à luz (Almeida et al. 1998, Ronqui \& Lopes 2006). Dessa forma, com a utilização de várias metodologias, a assembleia de Scarabaeinae presente no ecossistema estudado poderá ser mais bem amostrada quando o desejo de inventariar esta fauna for o objetivo do estudo (Spector 2006). Informações básicas sobre a montagem das armadilhas podem ser obtidas em Borror et al. (1992) e Almeida et al. (1998).

O grupo pertence à Scarabaeoidea, uma superfamília caracterizada por possuir clava antenal lamelada, protórax frequentemente modificado para escavação (com coxas largas), protíbias usualmente denteadas externamente, venação reduzida nas asas posteriores, quatro túbulos de Malpighi, e a larva do tipo escarabeiforme (curvada em forma de "C") (Cambefort 1991, Lawrence \& Britton 1994, Lawrence \& Newton 1995, Ratcliffe \& Jameson 2004). Scarabaeidae agrupa um número variado de subfamílias conforme diferentes autores, não havendo, até o momento, um consenso sobre grupos que ora são elevados ao status de família ora são tidos como subfamílias (Kohlmann 2006). No Brasil, o grupo aqui descrito, ora tem sido citado como subfamília e, algumas vezes, elevado ao nível de família (Scarabaeinae $=$ Scarabaeidae sensu stricto $)$ em diferentes trabalhos. 
Scarabaeinae apresenta tamanho muito variado, desde poucos milímetros, como em Besourenga Vaz-de-Mello, 2008, Canthonella Chapin, 1930 e Degallieridium Vaz-de-Mello, 2008, que possuem espécies com cerca de dois milímetros ou pouco menos (Ratcliffe \& Smith 1999; Vaz-de-Mello 2008), até mais de cinco centímetros, como ocorre em espécies do subgênero Megaphanaeus Olsoufieff, 1924 do gênero Coprophanaeus Olsoufieff, 1924 (Edmonds \& Zídek 2010). A coloração também é muito variada, desde preta opaca até uma gama de cores metálicas (Halffter \& Matthews 1966, Halffter \& Edmonds 1982, Young 1984), as quais podem ser aposemáticas, servir de comunicação intraespecífica ou mesmo ter a ver com o horário de atividade das espécies (Vulinec 1997, Hernández 2002).

O formato do corpo também varia conforme cada gênero, sendo, em geral, espécies com corpo oval. Contudo há espécies, como em Eurysternus Dalman, 1824, que possuem corpo achatado dorso- ventralmente e o lado dos élitros são quase paralelos, resultando em um aspecto retangular (Génier 2009, Hernández et al. 2011). Em várias espécies há dimorfismo sexual, sendo que em diversos grupos os machos podem possuir grandes cornos, utilizados em atividades dentro de suas galerias e, frequentemente, em disputas reprodutivas por fêmeas (Emlen 2008).

A diferenciação de Scarabaeinae para as demais subfamílias ou grupos próximos é fácil, e pelo menos os gêneros ocorrentes no Brasil podem ser diagnosticados, em relação a todos os demais coleópteros, pela seguinte diagnose: antenas lameladas, clavas com três lamelas, clípeo cobrindo as mandíbulas e labro, sendo estes membranosos; pigídio exposto quase totalmente, em geral vertical em relação ao eixo do corpo, mas às vezes em posição ventral, e tíbias posteriores com único esporão apical. Detalhes morfológicos podem ser visualizados nas Figuras 1 e 2.
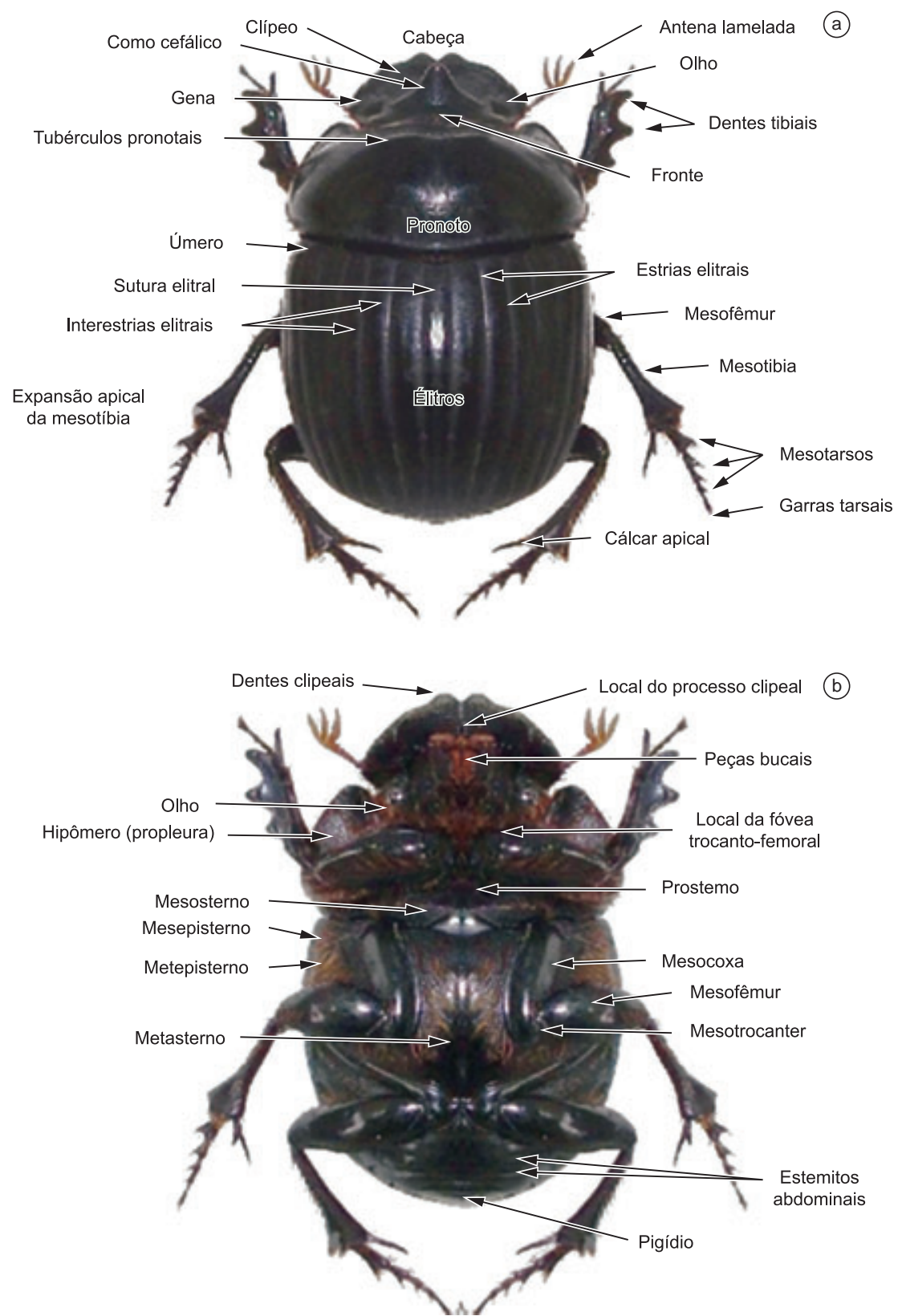

Figura 1. Morfologia externa básica de Scarabaeinae em vista a) dorsal; e b) ventral. Macho de Dichotomius nisus (Olivier, 1789).

Figure 1. Scarabaeinae basic external morphology in a) dorsal; and b) ventral view. Male of Dichotomius nisus (Olivier, 1789). 

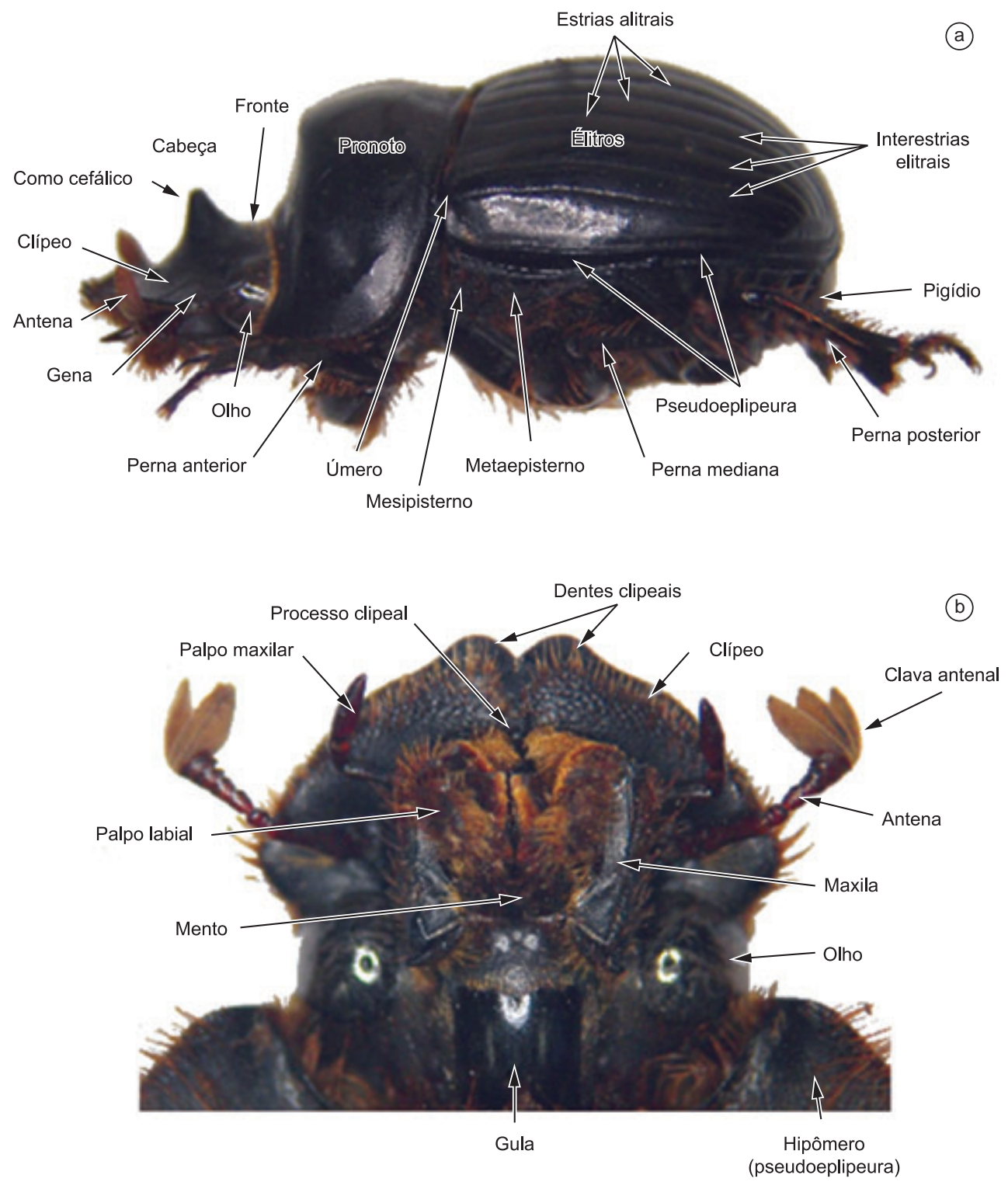

Figura 2. Morfologia externa lateral do a) corpo; e b) ventral da cabeça de Scarabaeinae. Macho de Dichotomius nisus (Olivier, 1789).

Figure 2. Lateral external morphology of a) body; and b) ventral portion of head of Scarabaeinae. Male of Dichotomius nisus (Olivier, 1789).

Estudos filogenéticos que levam em consideração características morfológicas e/ou moleculares têm contribuído com a elucidação de suposições sobre a mais correta relação dos grupos familiares e dentro de Scarabaeinae (por exemplo, Browne \& Scholtz 1999, Philips et al. 2004, Ocampo \& Hawks 2006, Monaghan et al. 2007, Vaz-de-Mello 2007b). Chaves dicotômicas de identificação de espécies podem ser encontradas em revisões recentes de gêneros, enquanto Vaz-deMello et al. (2011) trazem uma chave para os gêneros e subgêneros de Scarabaeinae americanos.

Chave para as espécies de Scarabaeinae de Santa Maria, Rio Grande do Sul (Os números correspondem à caracterização de gêneros e as letras à caracterização das espécies pertencentes ao gênero identificado)

Esta chave foi adaptada de Vaz-de-Mello et al. (2011) e conta com imagens da maioria das espécies e de estruturas morfológicas referidas na mesma. Em nível específico, as descrições seguem Pessôa e Lane (1941), Edmonds (1994, 2000), Edmonds \& Zídek (2010), Génier (1996, 2009) e Vaz-de-Mello (2008), ou de características observadas pelos autores. As 35 espécies incluídas na chave fazem parte do trabalho de campo da dissertação de mestrado do primeiro autor; outros dois táxons referidos na literatura para Santa Maria também são incluídos (Ontherus appendiculatus [Mannerheim, 1829] citada por Génier [1996] e Trichillum externepunctatum Preudhomme de Borre, 1886 citada por Vaz-de-Mello [2008]). Todas as espécies já haviam sido registradas para o estado (observação pessoal dos autores). Com exceção de uma espécie comum de Ontherus Erichson, 1847 (O. sulcator [Fabricius, 1775]) e de T. externepunctatum, todas as demais espécies com identificação confirmada são novos registros para a região central do Rio Grande do Sul.

Os gêneros desta chave, com respectivo número aproximado de espécies que ocorrem nas Américas, são: Ateuchus Weber, 1801 (85), Canthidium Erichson, 1847 (168), Canthon Hoffmannsegg, 1817 (190), Coprophanaeus Olsoufieff, 1924 (38), Deltochilum Eschscholtz, 1822 (81), Dichotomius Hope, 1838 (161), Eurysternus Dalman, 1824 (53), Homocopris Burmeister, 1846 (8), Ontherus Erichson, 1847 (59), Onthophagus Latreille, 1802 (151), Phanaeus MacLeay, 1819 (78), 
Guia de identificação das espécies de Scarabaeinae de Santa Maria, RS

Sulcophanaeus Olsoufieff, 1924 (20), Trichillum Harold, 1868 (11) e Uroxys Westwood, 1842 (60).

1. Corpo retangular, lados dos élitros paralelos a subparalelos; mesoescutelo visível (a olho nu ou pouco aumento) entre as bases dos élitros (Figura 3); mesocoxas paralelas ao eixo longitudinal do corpo, posicionadas externamente em relação ao metasterno (Figura 5); élitros com carena lateral que delimita a ampla pseudoepipleura; palpos labiais com dois palpômeros
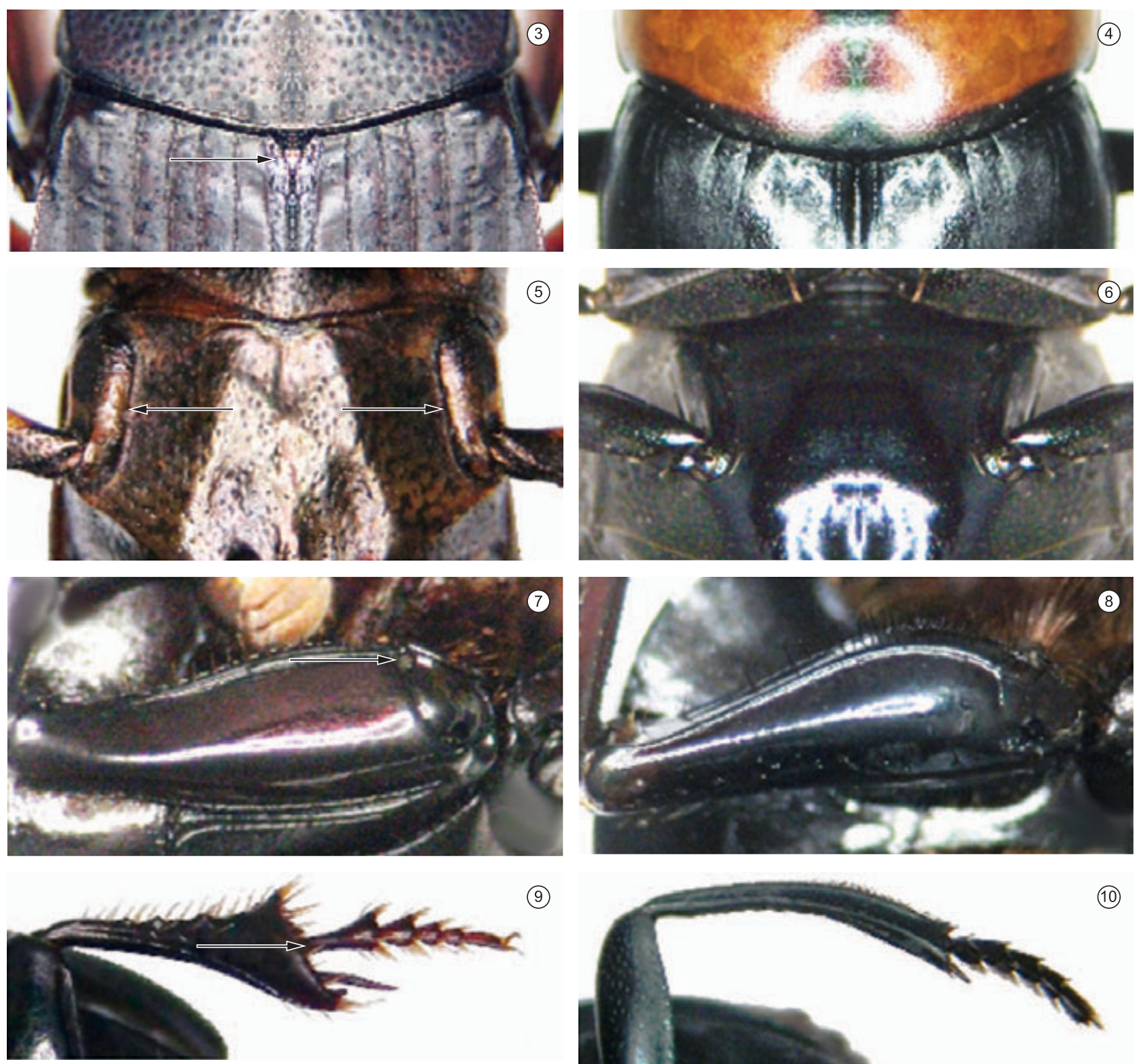

(9)
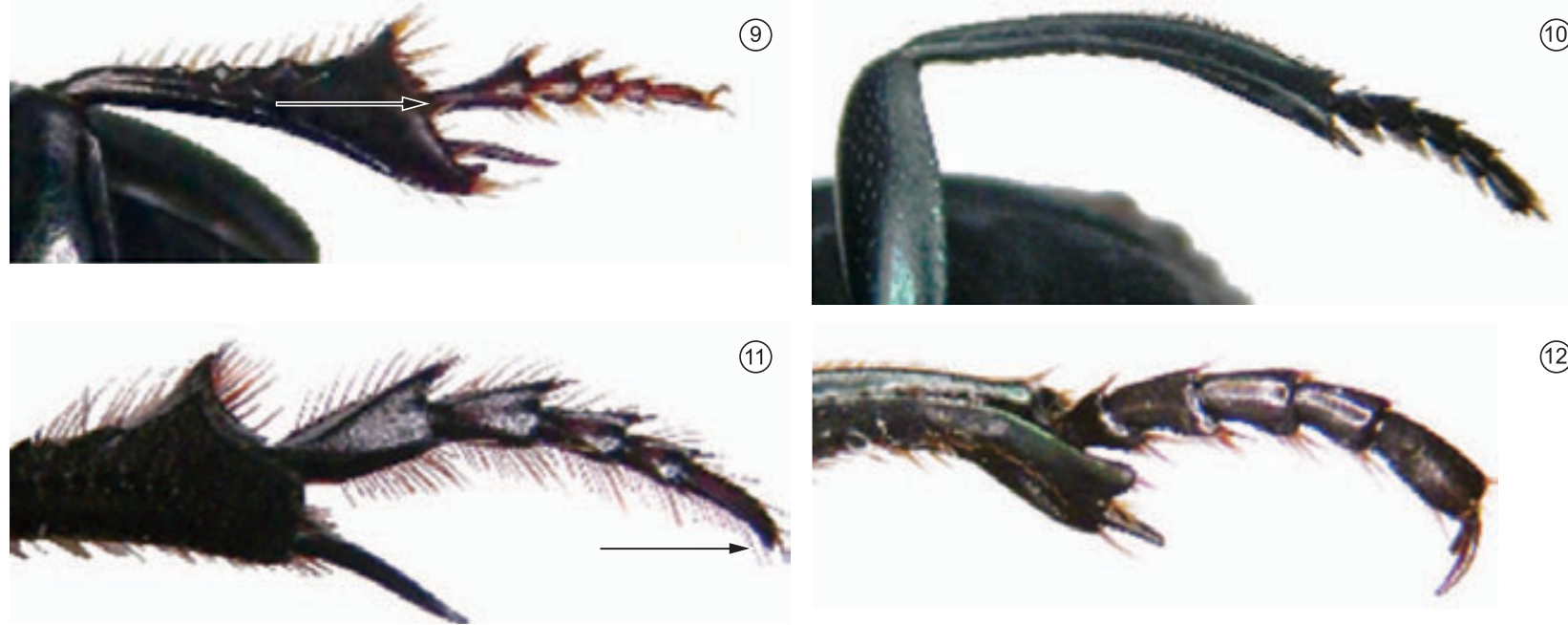

(12)

Figuras 3-12. Base dos élitros com: 3) mesoescutelo visível; e 4) não visível; 5) mesocoxas paralelas; e 6) oblíquas em relação ao eixo longitudinal do corpo; 7) fêmur anterior com; e 8) sem fóvea trocanto-femoral; 9) primeiro tarsômero posterior mais longo que os três seguintes combinados; e 10) tarsômero normal; 11) tarsômeros apicais médios e posteriores sem; e 12) com garras tarsais.

Figures 3-12. Elytra basis with: 3) mesoscutelum visible; and 4) not visible; 5) mesocoxae parallel; and 6) oblique to long axis of body; 7) front femur with; and 8) without foveae trochantofemoral; 9) first hind tarsomere with length greater than the following three combined; and 10) normal tarsomere; 11) middle and hind apical tarsomeres without; and 12) with tarsal claws. 
Eurysternus Dalman, 1824 .

1A. Tamanho inferior a oito milímetros, coloração cinzaescura, corpo com pilosidade dorsal desigual, com cerdas longas misturadas a curtas; pronoto e cabeça com pontuações circulares irregulares bem próximas; estrias elitrais sulcadas, delimitadas por elevações laterais e com uma fileira de cerdas

Eurysternus aeneus Génier, 2009 (Figura 33)

1A'. Tamanho superior a $10 \mathrm{~mm}$, coloração dorsal parda ou marrom-escura, cerdas longas, quando presentes, restritas à região apical dos élitros $1 \mathrm{~B}$

1B(1A'). Fêmures médios e posteriores unicolores, bruscamente alargados na metade apical e posteriormente sem espinhos; pronoto sem mancha gutiforme no meio da parte anterior; comprimento $10-13 \mathrm{~mm}$

\section{Eurysternus parallelus Castelnau, 1840 (Figura 34)}

1B'. Fêmures médios e posteriores com pelo menos o ápice muito mais claro que a base, não bruscamente alargados apicalmente; fêmures posteriores com um espinho na parte posterior; pronoto com mancha brilhante gutiforme no meio da parte anterior; comprimento $12-18 \mathrm{~mm}$

\section{Eurysternus caribaeus (Herbst, 1789) (Figura 35)}

1'. Corpo arredondado ou oval; mesoescutelo completamente coberto pelos élitros (Figura 4), ponta do mesoescutelo, se exposta, minúscula, visível apenas sob grande aumento (25x); mesocoxas não paralelas ao eixo longitudinal do corpo (Figura 6), normalmente formando ângulo entre si .............. 2

2(1'). Perna anterior com fóvea trocanto-femoral (Figura 7) ....3

2'. Perna anterior sem fóvea trocanto-femoral (Figura 8).......4

3(2). Último esternito abdominal amplamente expandido no meio, o qual cobre todo o disco do abdome, demais esternitos visíveis apenas nas laterais do abdome; corpo oval, acinzentado a negro; pseudoepipleura forma duas sinuosidades laterais, a posterior que é angulada (à altura da metacoxa) cobre parcialmente a verdadeira epipleura; dentes clipeais contínuos com a borda anterior do clípeo

\section{Trichillum externepunctatum Preudhomme de Borre, 1886}

3'. Último esternito abdominal não cobre totalmente o disco, demais esternitos visíveis e diferenciáveis também no meio do abdome; superfície dorsal polida e brilhante, com sulco longitudinal profundo em cada lado do pronoto; tegumento marrom-escuro a preto

Uroxys aff. terminalis Waterhouse, 1891 (Figura 36)

4(2'). Comprimento do primeiro tarsômero posterior maior que a soma dos três tarsômeros seguintes (Figura 9); clípeo de ambos os sexos sem dentes; machos podem apresentar dois pequenos chifres

Onthophagus Latreille, 1802 ... 4A

4A. Coloração preta a marrom-escura, brilhante; pronoto glabro com pontuações; interestrias elitrais sulcadas, bordos dos sulcos formam duas linhas; sem setas

\section{Onthophagus catharinensis Paulian, 1936 (Figura 37)}

4A'. Coloração do pronoto e/ou dos élitros esverdeada, avermelhada ou preta, opaca; pronoto pontuado com esparsa pilosidade; interestrias elitrais com setas
Onthophagus aff. tristis Harold, 1873 (Figuras 38 e 39)

4'. Comprimento do primeiro tarsômero posterior menor que o comprimento combinado dos três tarsômeros seguintes (Figura 10); clípeo geralmente com dentes clipeais, às vezes, inconspícuos (não notável) ............................................. 5

5(4'). Tarsos médios e posteriores sem garras (Figura 11); lamela antenal basal côncava apicalmente (Figura 13) ........ 6

5'. Tarsos médios e posteriores com garras (Figura 12); lamela antenal normal (Figura 14) .................................... 8

6(5). Margem clipeal com emarginação mediana profunda e aguda, com dois dentes agudos, separados da borda lateral adjacente por emarginações externas (Figura 15)

Coprophanaeus Olsoufieff, 1924 ... 6A

6A. Coloração azulada, opaca; élitros com interestrias esculpidas ao longo de toda extensão; processo cefálico em ambos os sexos laminado e tridentado apicalmente; machos com tubérculos pronotais agudos e direcionados anterolateralmente

Coprophanaeus milon (Blanchard, 1845) (Figuras 40 e 41)

6A'. Coloração azul a vermelha metálica brilhante; interestrias elitrais lisas, sem microescultura; processo cefálico nos machos transformado em corno cilíndrico simples, pronoto com três sulcos e duas projeções medianas

Coprophanaeus saphirinus (Sturm, 1826) (Figuras 42 e 43)

6'. Margem clipeal sem emarginação profunda e aguda, no máximo com dois dentes medianos inconspícuos (Figura 16) .... 7

$7\left(6^{\prime}\right)$. Porção anterior da carena circumnotal (borda anterior do pronoto) inteira, não interrompida atrás de cada olho (Figura 17); ângulo anterior do pronoto (ao lado de cada olho) quase reto, o qual forma um pequeno dente anterior; processo cefálico como um dente agudo triangular; esternitos abdominais com pontuações de setas em toda a extensão; pronoto medianamente preto e lateralmente verde-metálico, élitros verde-azulados

Sulcophanaeus rhadamanthus (Harold, 1875) (Figuras 44 e 45)

7'. Porção anterior da carena circumnotal interrompida atrás de cada olho (Figura 18); macho: com corno cefálico espatulado apicalmente; amplo sulco mediano bilobado no pronoto; fêmea: pronoto convexo, com mancha central preta; coloração esverdeada

Phanaeus splendidulus (Fabricius, 1781) (Figuras 46 e 47)

$8\left(5^{\prime}\right)$. Tíbias médias e posteriores não alargadas para o ápice, ou apenas fraca e gradualmente (Figura 19) 9

8'. Tíbias médias, e geralmente também as posteriores, abruptamente alargadas para o ápice (Figura 20); largura no ápice superior a um quinto do comprimento da tíbia ......... 10

9(8). Ápice de algumas interestrias elitrais discais com curtas carenas ou tubérculos (Figura 21)

Deltochilum Eschscholtz, 1822 ... 9A

9A. Pronoto preto e élitros avermelhados, com tubérculos arredondados pretos nas interestrias; nona interestria elitral (na pseudoepipleura) sem carena, algumas interestrias medianas com pontuações pretas evidentes; tarsos anteriores ausentes; porção interna das tíbias posteriores amplamente serreada nos machos

Deltochilum rubripenne (Gory, 1831) (Figura 48)

9A'. Pronoto e élitros da mesma cor $9 \mathrm{~B}$ 

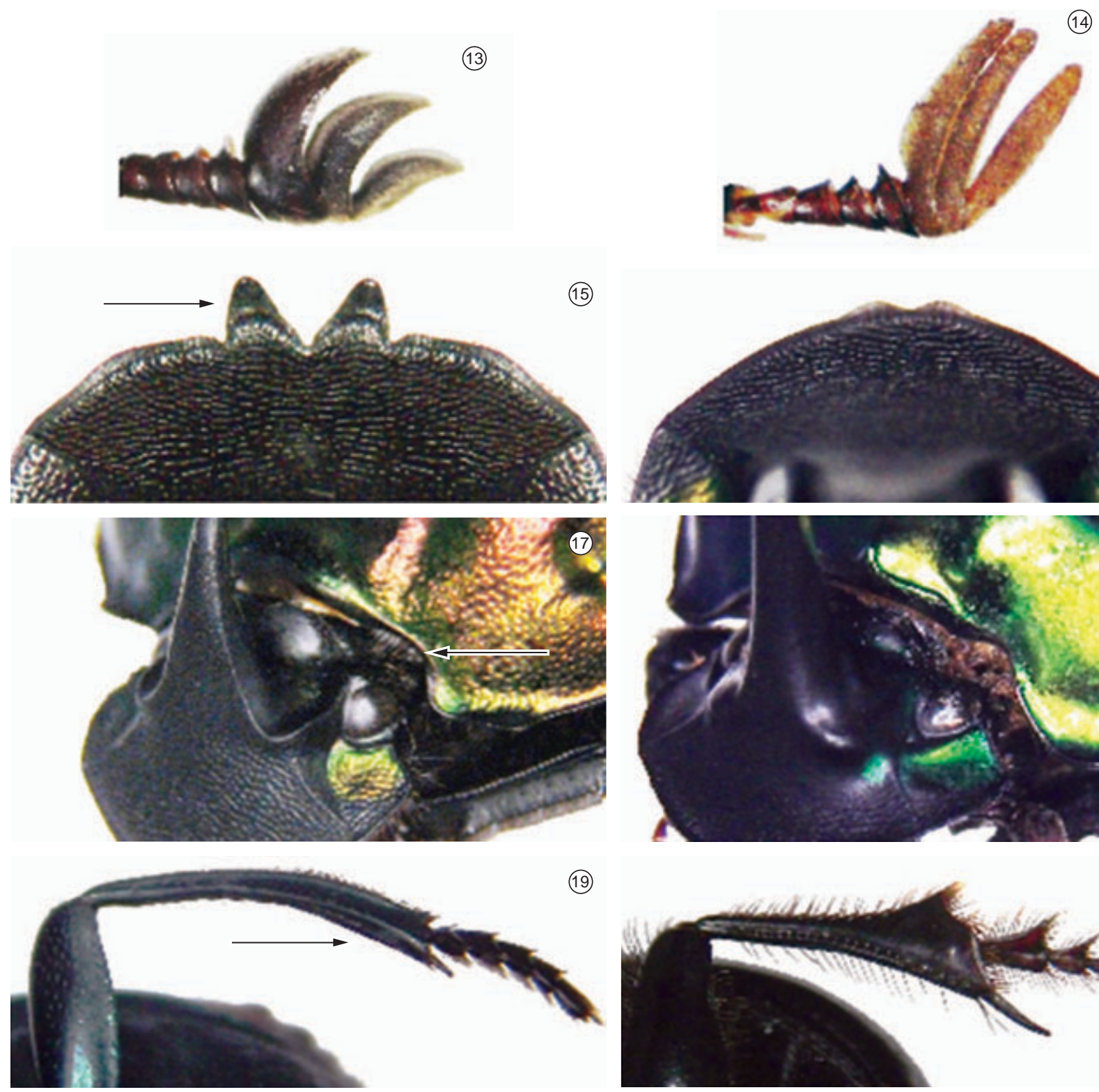

(14)

(15)
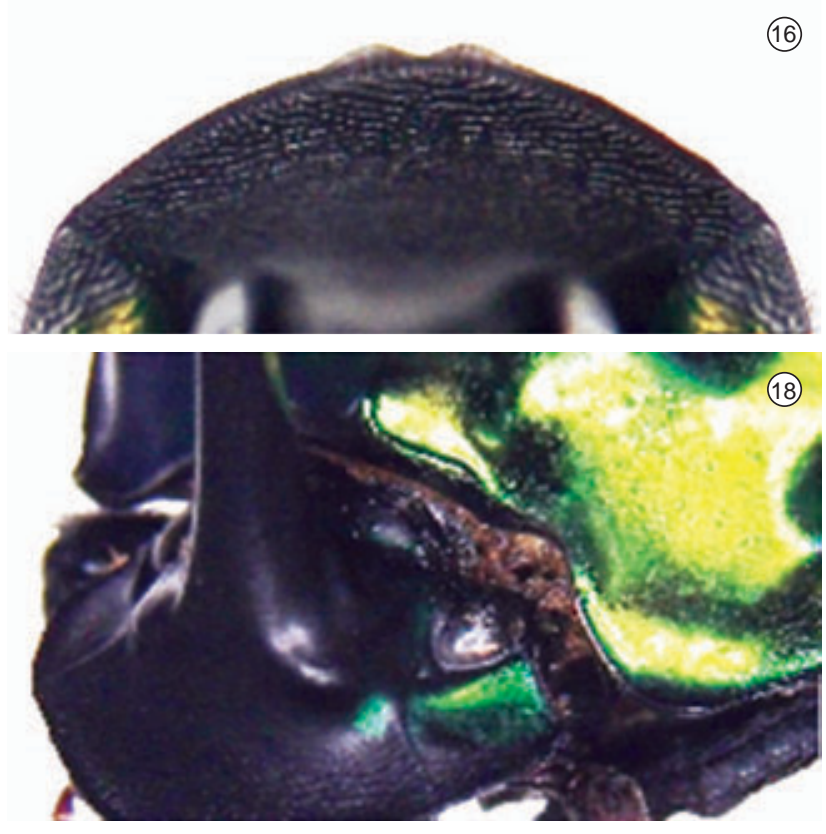

9
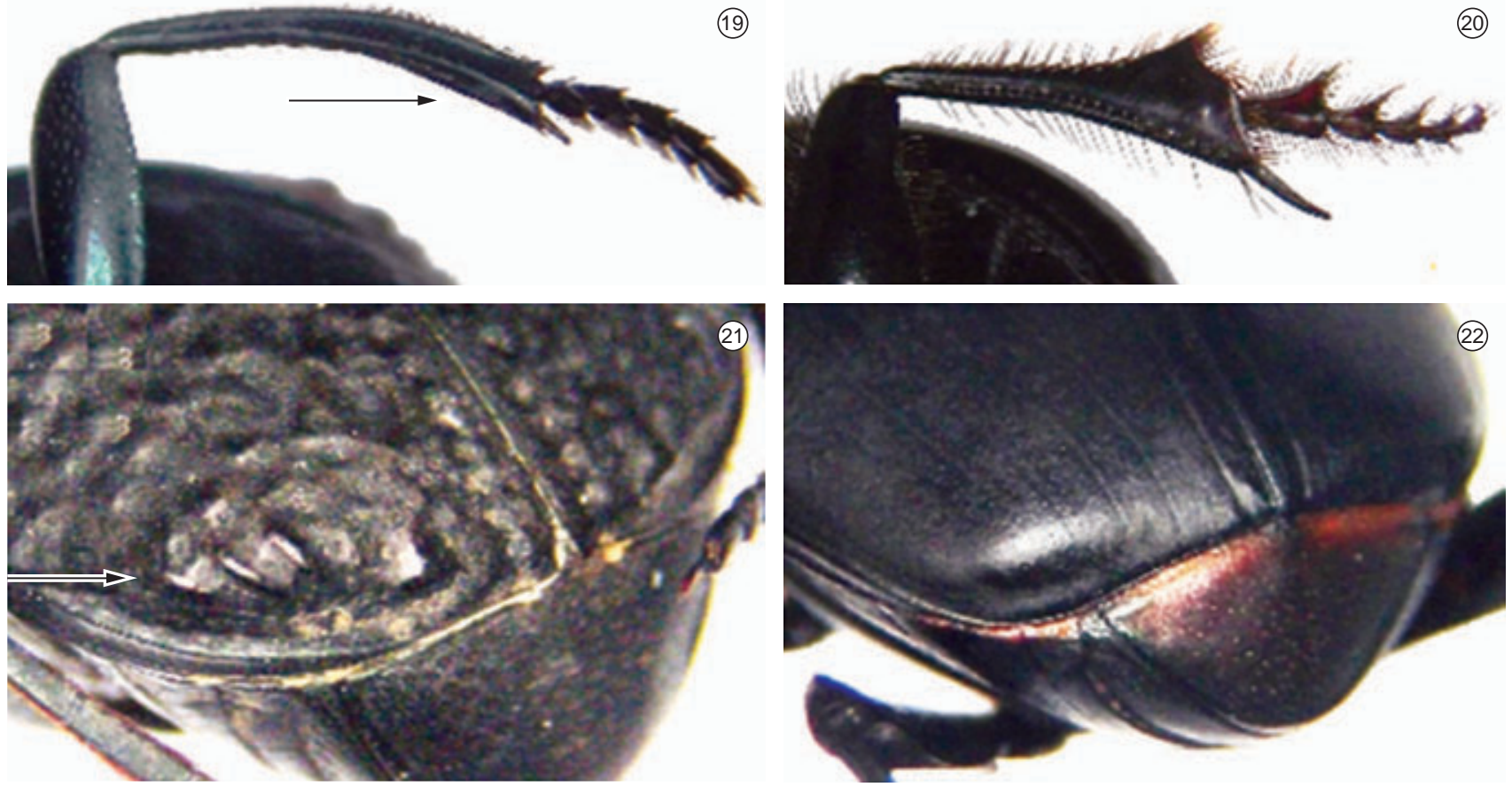

Figuras 13-22. 13) Lamela antenal côncava apicalmente; e 14) normal; 15) dentes clipeais agudos, com emarginações medianas e laterais; e 16) inconspícuos, sem emarginações; 17) carena circum-notal inteira; e 18) interrompida atrás de cada olho; 19) tíbia posterior fraca e gradualmente alargada para o ápice; e 20) abruptamente alargada para o ápice; 21) interestrias elitrais com; e 22) sem carenas na base dos élitros.

Figures 13-22. 13) Antennal lamella concave apically; and 14) normal; 15) clypeal teeth acute; with acutely median and lateral emarginations; and 16) conspicuous, without emarginations; 17) circum-notal carina entire; 18) and interrupted behind each eye; 19) hind tibiae not appreciably widened apically; and 20) abruptly widened apically; 21) elytral interstriae with; and 22) without apical carina. 
9B(9A'). Comprimento superior a $20 \mathrm{~mm}$, aspecto alargado, clípeo lateralmente sinuoso (externamente aos dentes centrais); coloração preta opaca

Deltochilum brasiliense (Castelnau, 1840) (Figura 49)

9B'. Comprimento inferior a $20 \mathrm{~mm}$, aspecto alongado, clípeo arredondado a cada lado dos dentes centrais; coloração completamente preta ou acinzentada brilhante ................... 9C

9C(9B'). Comprimento inferior a $12 \mathrm{~mm}$, coloração preta opaca; élitros com leves ondulações, não chegando a formar tubérculos

Deltochilum morbillosum Burmeister, 1848 (Figura 50)

9C'. Comprimento superior a $13 \mathrm{~mm}$, tegumento pretoacinzentado; élitros totalmente foveolados, com tubérculos transversais entre as fóveas

\section{Deltochilum sculpturatum Felsche, 1907 (Figura 51)}

9'. Interestrias elitrais sem carenas ou tubérculos no ápice (Figura 22), no máximo com uma carena lateral que pode ser quase completa

Canthon Hoffmannsegg, 1817 ... 9'A

9'A. Face ventral do fêmur posterior não marginada anteriormente; carena propleural (hipomeral) transversal quase completamente presente; clípeo com dois dentes largos e agudos, com forte escavação mediana; tegumento castanho-amarelado, pronoto com mancha preta na porção mediana posterior, pernas médias e posteriores amareladas

Canthon oliverioi Pereira \& Martínez, 1956 (Figura 52)

9'A'. Face ventral do fêmur posterior com fina margem anterior .................................................................... 9'B

9'B(9'A'). Pigídio e propigídio não separados por carena transversal ................................................................ 9'

9'B'. Pigídio e propigídio ao menos parcialmente separados por carena transversal ... 9'D

9'C(9'B). Comprimento inferior a $10 \mathrm{~mm}$, coloração parda ou marrom-escura 9E

9'C'. Comprimento geralmente superior a $10 \mathrm{~mm}$, tegumento preto, pronoto amarelado com cinco manchas pretas arredondadas, dispostas transversalmente ao eixo do corpo

Canthon quinquemaculatus (Castelnau, 1840) (Figura 53)

9'D(9'B'). Borda anterior do profêmur com dentículos; clípeo com dois dentes inconspícuos; tegumento verde-brilhante

Canthon latipes Blanchard, 1845 (Figura 54)

9'D'. Fêmur anterior não denticulado; clípeo com dois dentes afilados; élitros azul-escuros a pretos ...................... 9' $\mathrm{F}$

9'E(9'C). Pernas e élitros pardo-avermelhados, pronoto preto, opaco

Canthon aff. luctuosus Harold, 1868 (Figura 55)

9'E'. Pernas e élitros marrom-escuros, pronoto com manchas marrons-brilhantes

Canthon amabilis Balthasar, 1939 (Figura 56)

9'F(9'D'). Corpo azul-escuro ou verde-escuro

Canthon chalybaeus Blanchard, 1845 (Figura 57)

9'F'. Cabeça e pronoto vermelhos, élitros geralmente negros

Canthon lividus Blanchard, 1845 (Figura 58)

$10\left(8^{\prime}\right)$. Propleura (hipômero) fracamente escavada anteriormente, sem delimitação posteriormente (Figura 23); carena transversal propleural quase sempre ausente; ângulo interno apical da tíbia anterior obliquamente truncado $\left(>90^{\circ}\right)$ (Figura 25); se com aproximadamente $90^{\circ}$ ou fracamente agudo, então borda anterior do dente apical formando ângulo com a truncadura apical da tíbia 11

10'. Propleura (hipômero) profundamente escavada anteriormente, escavação delimitada posteriormente por área vertical separada da parte não escavada por carena transversal (Figura 24); ângulo interno apical da tíbia anterior com aproximadamente $90^{\circ}$ ou agudo (Figura 26), borda anterior do dente apical contínua (sem formar ângulo) com a truncadura apical da tíbia

Ateuchus Weber, 1801 ... 10'A

10'A. Clípeo bidentado, dentes arredondados e próximos; carena frontoclipeal presente; estrias elitrais com marcada pontuação; comprimento próximo a $10 \mathrm{~mm}$

Ateuchus aff. robustus (Harold, 1868) (Figura 59)

10'A'. Clípeo com grande expansão entre os pequenos dentes; carena frontoclipeal ausente; estrias elitrais fracamente pontuadas; região ântero-apical dos élitros com pequena depressão medial; tamanho geralmente inferior a oito milímetros

Ateuchus aff. carbonarius (Harold, 1868) (Figura 60)

11(10). Ângulo interno apical da tíbia anterior com aproximadamente $90^{\circ}$ ou agudo; mesosterno muito curto, verticalmente posicionado; processo clipeal ausente, indicado por fraca carena longitudinal; metasterno geralmente convexo; porção posterior das tíbias médias e posteriores dilatadas internamente (Figura 27), borda externa reta

Canthidium Erichson 1847 ... 11A

11A. Margem posterior do pronoto bordeada por fileira de pontos; tamanho próximo a $10 \mathrm{~mm}$, coloração azul-, verde- ou marrom-escura

Canthidium aff. dispar Harold, 1867 (Figuras 61 e 62)

11A'. Margem posterior do pronoto sem fileira basal de

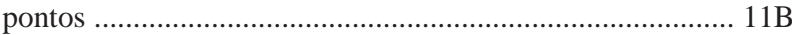

11B(11A'). Comprimento inferior a cinco milímetros; estrias elitrais fracamente pontuadas, pontuação visível somente sob grande aumento; tegumento preto

Canthidium sp. (Figura 63)

11B'. Comprimento superior a cinco milímetros; estrias elitrais com pontuação definida ...................................... 11C

11C(11B'). Comprimento próximo a sete milímetros; porção mediana do clípeo com três pequenas projeções; dentes clipeais inconspícuos, sem emarginação mediana profunda; metasterno finamente pontuado; tegumento preto

Canthidium aff. trinodosum Boheman, 1858 (Figura 64)

$11 \mathrm{C}$ '. Comprimento próximo a $10 \mathrm{~mm}$; porção mediana do clípeo com projeção transversal proeminente, com leve depressão posterior; dentes clipeais distintos, com profunda emarginação mediana; metasterno liso e sem pontuação entre as mesocoxas; coloração variada

Canthidium moestum Harold, 1867 (Figuras 65-69)

11'. Ângulo interno apical da tíbia anterior geralmente maior que $90^{\circ}$; mesosterno bem desenvolvido, horizontal; processo clipeal em forma de tubérculo bifurcado ou carena transversal (podendo estar ausentes); metasterno geralmente achatado; tíbias médias e posteriores dilatadas interna e externamente (Figura 28) 12 


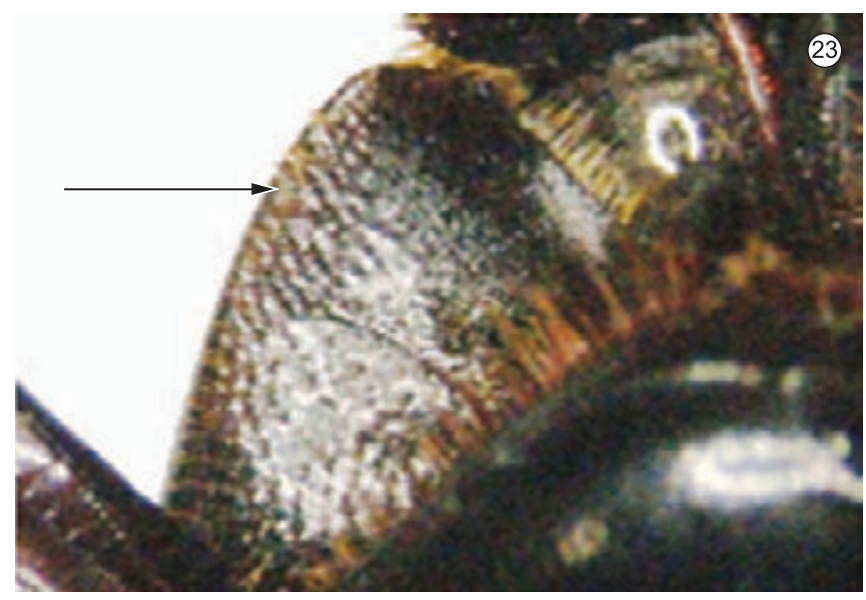

(25)
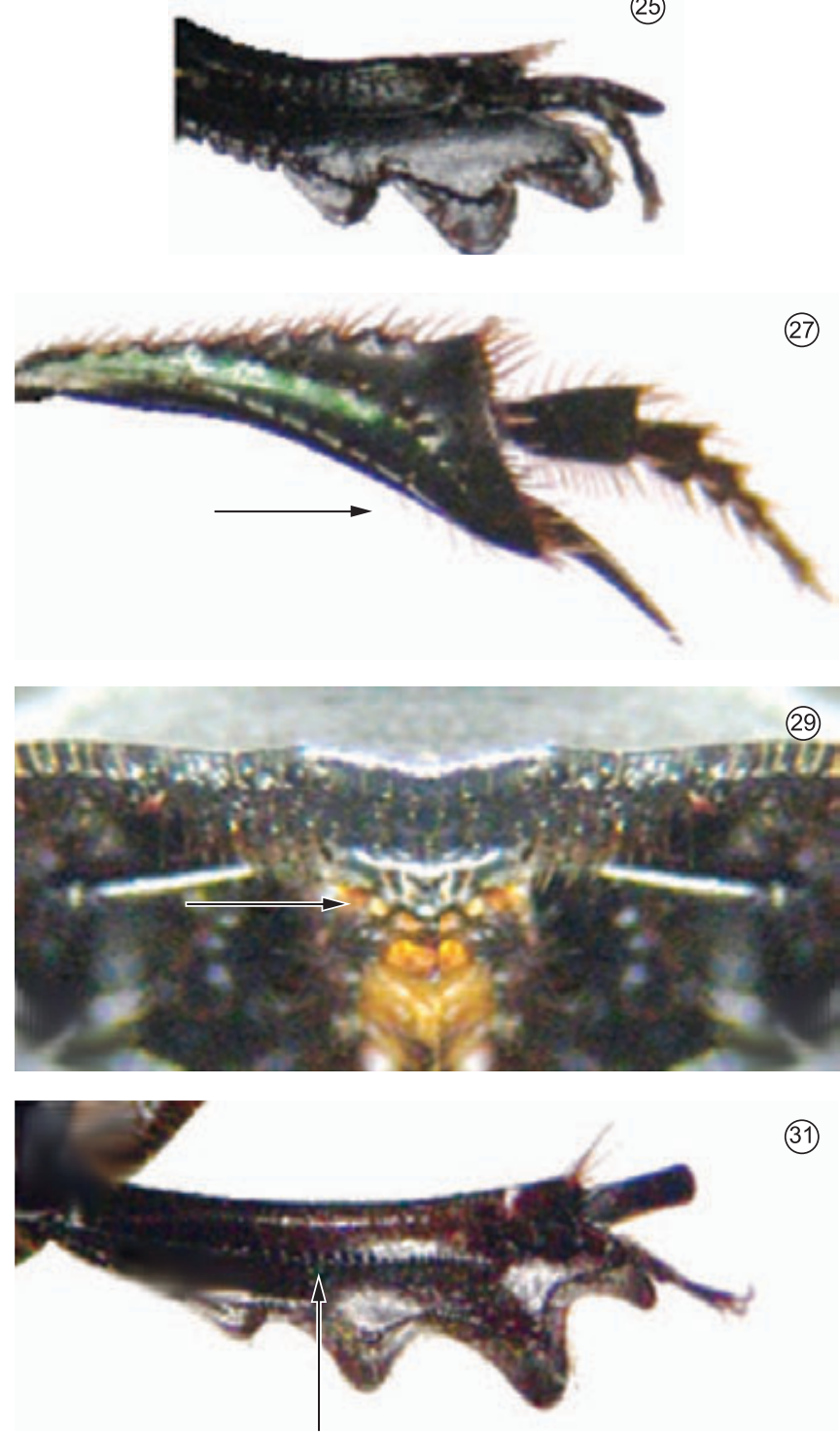

(31)
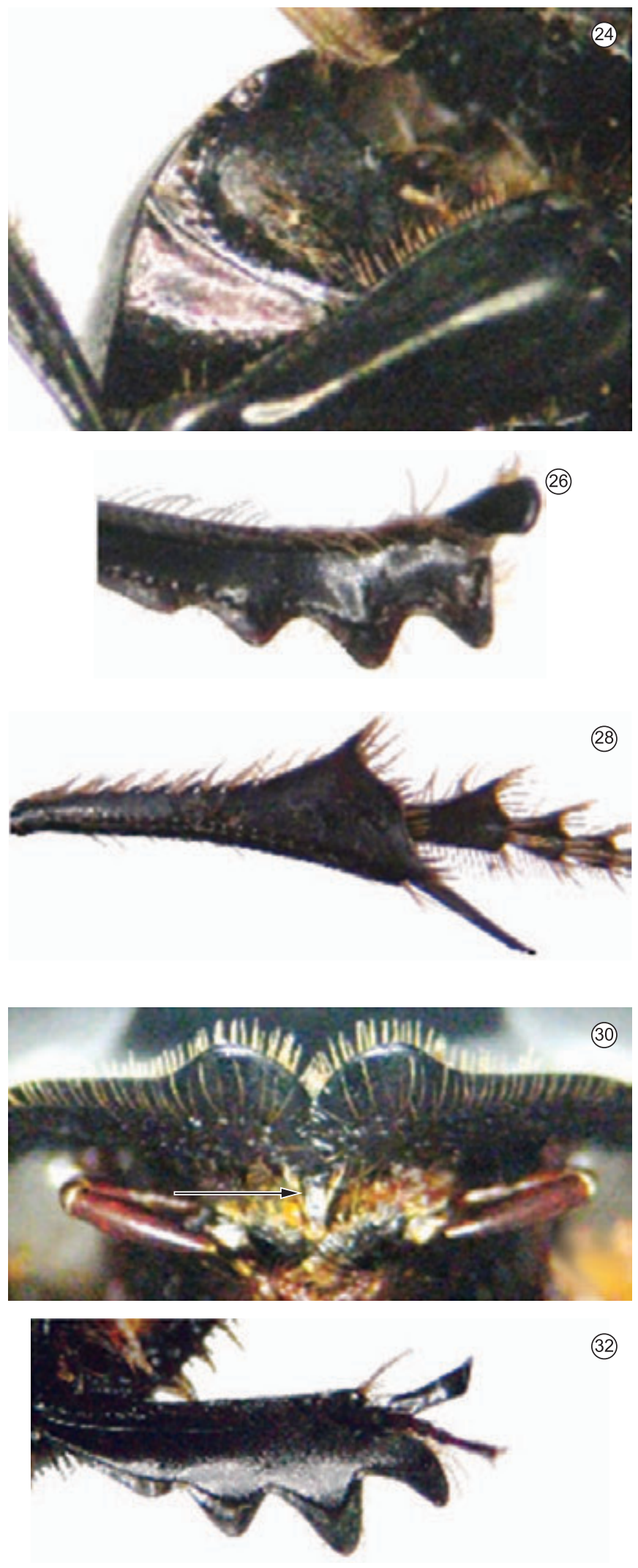

(32)

Figuras 23-32. 23) Hipômero (propleura) fracamente; e 24) profundamente escavado anteriormente; 25) ângulo interno apical da tíbia anterior obliquamente truncado; e 26) com ângulo reto; 27) tíbia média dilatada internamente; e 28) dilatada interna e externamente; 29) processo clipeal ventral transversal; e 30) coniforme; 31) carena ventral medial da tíbia anterior interrompida; e 32) não interrompida por setas.

Figures 23-32. 23) Hypomeron (propleuron) not deeply; and 24) deeply excavated anteriorly; 25) inner apical angle of front tibia obliquely truncate; and 26 with straight angle; 27) middle tibiae dilated internally; and 28) dilated internally and externally; 29) ventral clypeal process transverse; and 30) coniform; 31) middle ventral carina of front tibiae interrupted; and 32) not interrupted by setae. 
12(11'). Processo clipeal ventral transversal (Figura 29), em vista frontal obtusamente triangular ou sub-retangular; cálcar tibial posterior espatulado ou truncado 13

12'. Processo clipeal ventral coniforme (Figura 30), geralmente bifurcado apicalmente, às vezes inserido em uma carena longitudinal; cálcar tibial posterior claramente bifurcado apicalmente ou dentado subapicalmente

Dichotomius Hope, 1838 ... 12'A

12'A. Borda da cabeça angulosa na junção entre o clípeo e a gena; processo cefálico coniforme, bidentado apicalmente nas fêmeas e unidentado nos machos; pilosidade metasternal esparsa; último esternito abdominal da fêmea prolongado além do ápice do pigídio; comprimento inferior a $15 \mathrm{~mm}$

Dichotomius aff. acuticornis (Luederwaldt, 1930) (Figura 70)

12'A'. Borda lateral da cabeça arredondada, sem ângulo na junção clípeo-genal; pilosidade metasternal densa; último esternito abdominal da fêmea nunca prolongado além do ápice do pigídio 12'B

$12^{\prime} \mathrm{B}(12$ 'A'). Macho com processo cefálico laminar protuberante e dois tubérculos pronotais anteriores; fêmea com processo cefálico menor e levemente divido medianamente

Dichotomius assifer (Eschscholtz, 1822) (Figuras 71 e 72)

12 'B'. Macho com processo cefálico coniforme grosso, às vezes bidentado apicalmente; fêmea com processo cefálico menor, expandido lateralmente na base, com dois dentes separados

Dichotomius nisus (Olivier, 1789) (Figuras 73 e 74)

13(12). Carena ventral medial da tíbia anterior interrompida por setas (Figura 31); primeiro e segundo antenômeros da clava antenal com uma fóvea na face distal; mesepisterno com carena paralela à borda posterior; esculturas laterais do pronoto e clípeo lisas, normais

Ontherus Erichson, 1847 ... 13A

13A. Esternitos abdominais glabros medianamente, com curtas setas ao longo da borda posterior da metacoxa; borda posterior da metacoxa não serrada; porção posterior do metasterno liso; estriais elitrais sem pontuação definida

Ontherus sulcator (Fabricius, 1775) (Figura 75)

13A'. Esternitos abdominais medianamente pilosos, setas semelhantes àquelas da porção lateral do metasterno $13 \mathrm{~B}$

13B(13A'). Borda posterior da metacoxa finamente serrada; maioria das pontuações nos lobos laterais do mestasterno arredondada, claramente delimitada; porção posterior do metasterno com depressão foliar; estrias elitrais pontuadas

Ontherus azteca Harold, 1869 (Figura 76)

13B'. Borda posterior da metacoxa lisa; maioria das pontuações dos lobos laterais do metasterno oval, cada um com a borda posterior lateral fracamente indicada; margem pigidial geralmente completa; lobo médio do metasterno com no máximo minúsculas setas

Ontherus appendiculatus (Mannerheim, 1829)

13'. Carena ventral medial da tíbia anterior glabra (Figura 32); primeiro e segundo antenômeros da clava antenal sem fóvea distal; esculturas laterais do pronoto e clípeo normalmente irregulares; macho com processo cefálico espiniforme, com dois pequenos tubérculos pronotais ânteromedianos; fêmea com longa carena cefálica; coloração preta ou marrom-escura, opaca
Homocopris sp. (Figuras 77 e 78)

\section{Informações sobre as espécies de Scarabaeinae de Santa Maria, $R S$}

Os dados sobre alimentação e distribuição (apenas para as espécies seguramente identificadas) são baseados em dados da literatura e, principalmente, no trabalho de campo realizado em fragmentos florestais no município de Santa Maria, Rio Grande do Sul, Brasil.

\section{ATEUCHINI}

\section{Ateuchus aff. carbonarius}

O único exemplar capturado ocorreu em armadilha de queda iscada com fezes humanas em fragmento de floresta estacional decidual durante o mês de outubro de 2009 .

\section{Ateuchus aff. robustus}

Espécie coprófaga, muito atraída a fezes humanas. Poucos exemplares foram capturados em armadilhas de queda iscadas com carne apodrecida. Frequente durante todo o ano e parece se adaptar bem a ambientes pouco preservados.

\section{Trichillum externepunctatum}

Espécie de ampla distribuição pela América do Sul (Vaz-deMello 2008), que possui hábito alimentar coprófago, podendo nidificar em ninhos de outras espécies de Scarabaeinae (Martínez 1959). Também atraída por luz artificial (Martínez 1959, Link 1976). Imagens da espécie podem ser visualizadas em Vaz-de-Mello (2008).

\section{Uroxys aff. terminalis}

Espécie comum durante todo o ano, muito atraída a fezes humanas, mas também capturada em armadilhas de queda iscadas com carne e fruta apodrecidas. A atração por diferentes tipos de recursos pode ser fruto de processos evolutivos, pois algumas espécies deste gênero vivem em ninhos de formigas, possivelmente se alimentando da matéria orgânica ali presente (Halffter \& Matthews 1966; Vaz-de-Mello et al. 1998).

\section{COPRINI}

\section{Canthidium aff. dispar}

Encontrada em excrementos humanos, carne e fruta apodrecida; frequente durante todo o ano em Santa Maria.

\section{Canthidium moestum}

Espécie generalista (Silva et al. 2008, 2009), que se distribui pelo sul do Brasil, Argentina e Uruguai (Martínez 1959; Martínez \& Halffter 1986; González-Vainer \& Morelli 2008); frequente em ecossistemas campestres. Ocorreu principalmente durante a primavera e verão.

\section{Canthidium aff. trinodosum}

Possui hábito alimentar generalista, mas muito atraída por fezes humanas. Abundante durante todo o ano, principalmente em ecossistemas florestais mais preservados.

\section{Canthidium sp.}

Espécie generalista com preferência pela coprofagia. Foi muito frequente ao longo de todo o ano, registrada também em ecossistemas mais perturbados.

\section{Dichotomius aff. acuticornis}

Atraída por fezes humanas, carne e fruta apodrecida; ocorre durante a primavera e verão em ecossistemas florestais mais preservados. 

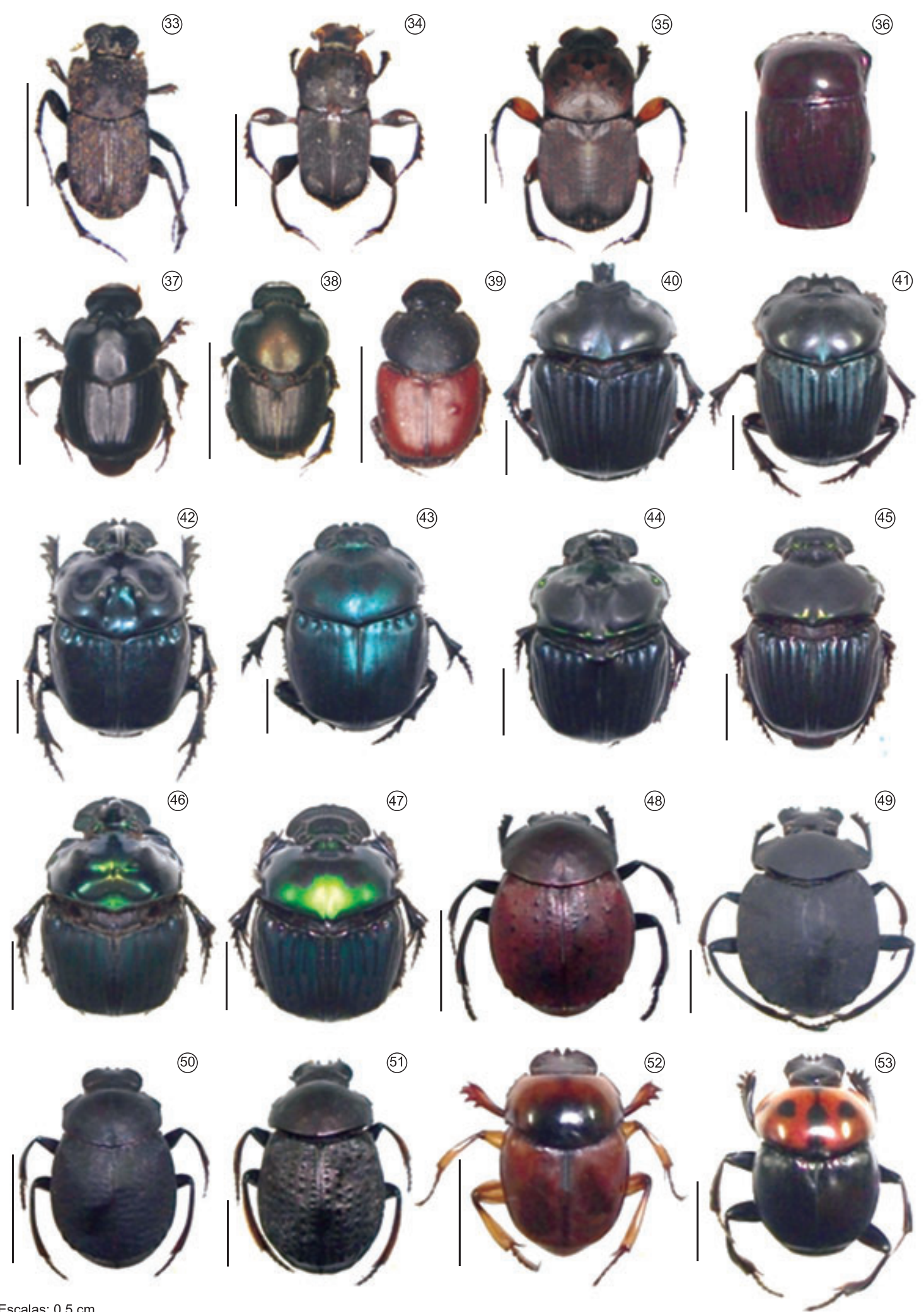

Escalas: $0,5 \mathrm{~cm}$

Figuras 33-53. 33) Eurysternus aeneus; 34) Eurysternus parallelus; 35) Eurysternus caribaeus; 36) Uroxys aff. terminalis; 37) Onthophagus catharinsensis; 38, 39) Onthophagus aff. tristis; 40, 41) Coprophanaeus milon (macho e fêmea); 42, 43) Coprophanaeus saphirinus (macho e fêmea); 44, 45) Sulcophanaeus rhadamanthus (macho e fêmea); 46, 47) Phanaeus splendidulus (macho e fêmea); 48) Deltochilum rubripenne; 49) Deltochilum brasiliense; 50) Deltochilum morbillosum; 51) Deltochilu sculpturatum; 52) Canthon oliverioi; 53) Canthon quinquemaculatus. Escalas: 0,5 cm.

Figures 33-53. 33) Eurysternus aeneus; 34) Eurysternus parallelus; 35) Eurysternus caribaeus; 36) Uroxys aff. terminalis; 37) Onthophagus catharinsensis; 38,39 ) Onthophagus aff. tristis (a and b forms); 40, 41) Coprophanaeus milon (male and female); 42, 43) Coprophanaeus saphirinus (male and female); 44, 45) Sulcophanaeus rhadamanthus (male and female); 46, 47) Phanaeus splendidulus (male and female); 48) Deltochilum rubripenne; 49) Deltochilum brasiliense; 50) Deltochilum morbillosum; 51) Deltochilum sculpturatum; 52) Canthon oliverioi; 53) Canthon quinquemaculatus. Scales: $0.5 \mathrm{~cm}$. 

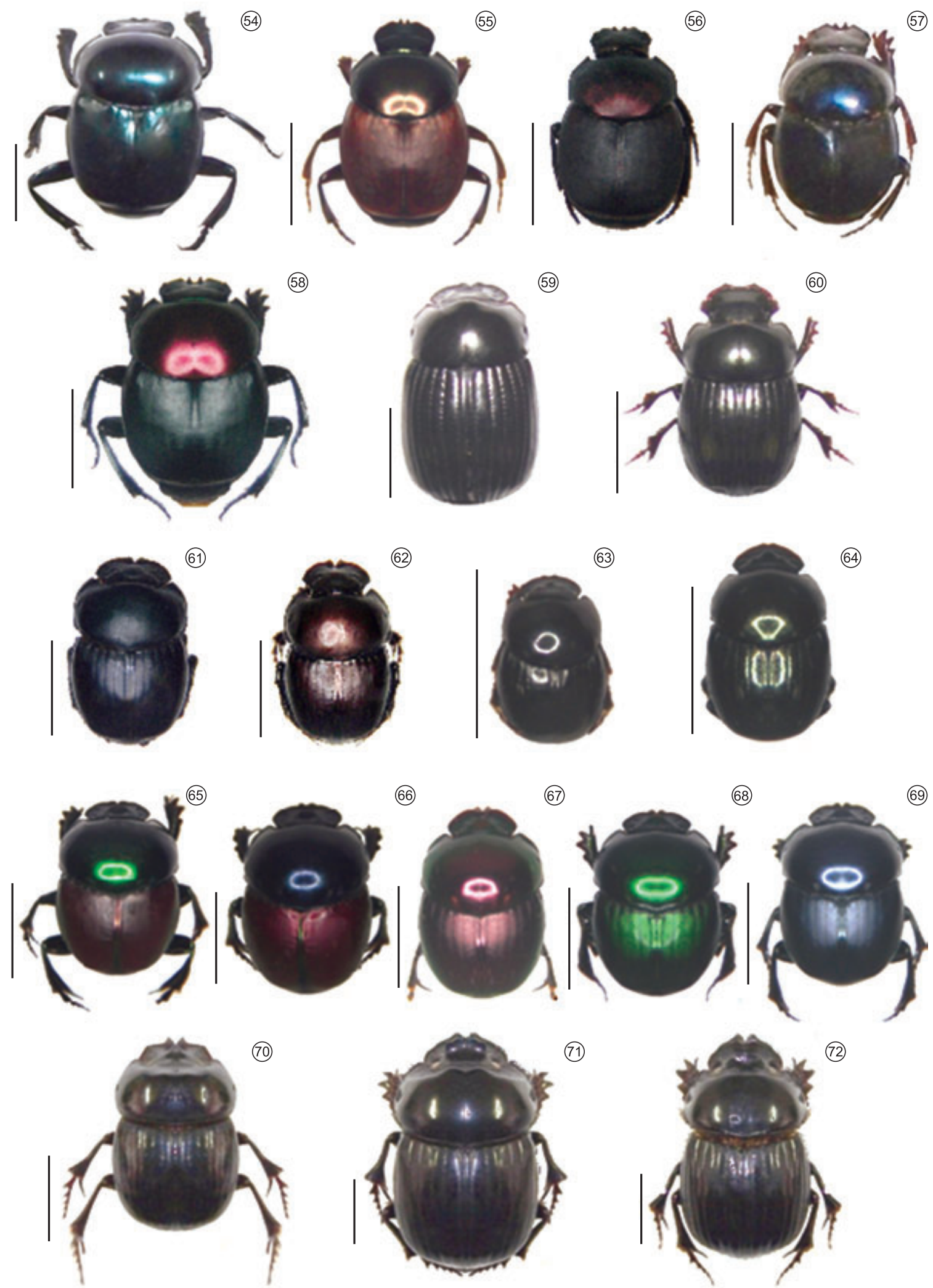

Escalas: $0,5 \mathrm{~cm}$

Figuras 54-72.54) Canthon latipes; 55) Canthon aff. luctuosus; 56) Canthon amabilis; 57) Canthon chalybaeus; 58) Canthon lividus; 59) Ateuchus aff. robustus; 60) Ateuchus aff. carbonarius; 61, 62) Canthidium aff. dispar (formas a e b); 63) Canthidium sp.; 64) Canthidium aff. trinodosum; 65-69) Canthidium moestum (formas a-e); 70) Dichotomius aff. acuticornis; 71, 72) Dichotomius assifer (macho e fêmea). Escalas: 0,5 cm.

Figures 54-72. 54) Canthon latipes; 55) Canthon aff. luctuosus; 56) Canthon amabilis; 57) Canthon chalybaeus; 58) Canthon lividus; 59) Ateuchus aff. robustus; 60) Ateuchus aff. carbonarius; 61, 62) Canthidium aff. dispar (a and b forms); 63) Canthidium sp.; 64) Canthidium aff. trinodosum; 65-69) Canthidium moestum (a-e forms); 70) Dichotomius aff. acuticornis; 71, 72) Dichotomius assifer (male and female). Scales: $0.5 \mathrm{~cm}$. 

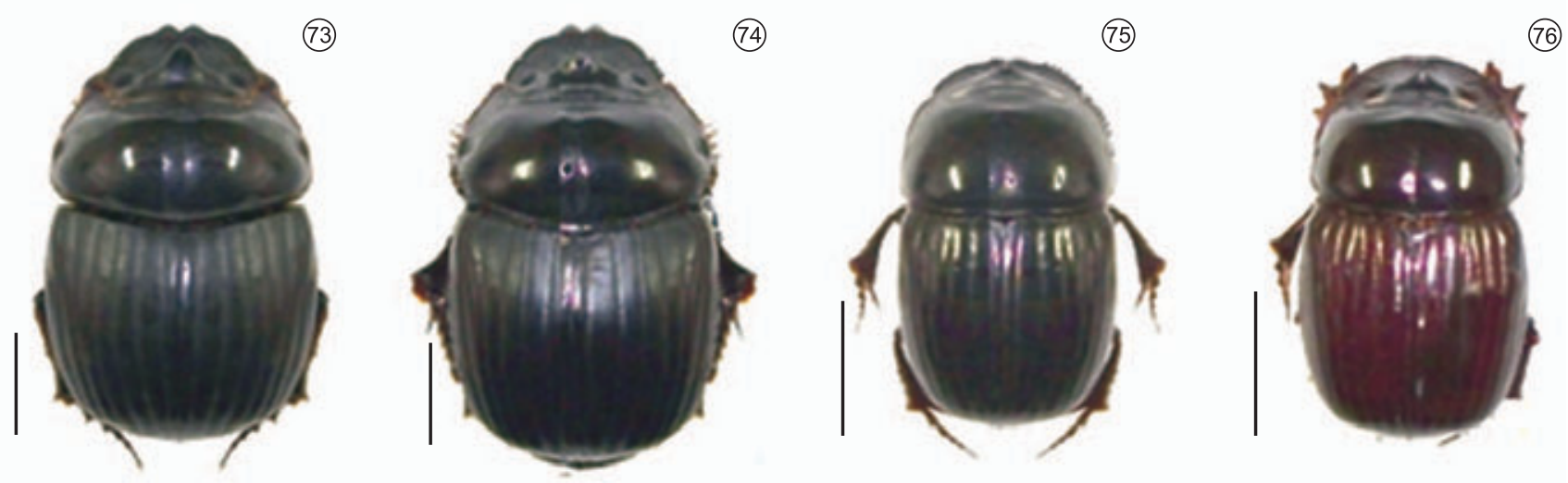

Escalas: $0,5 \mathrm{~cm}$
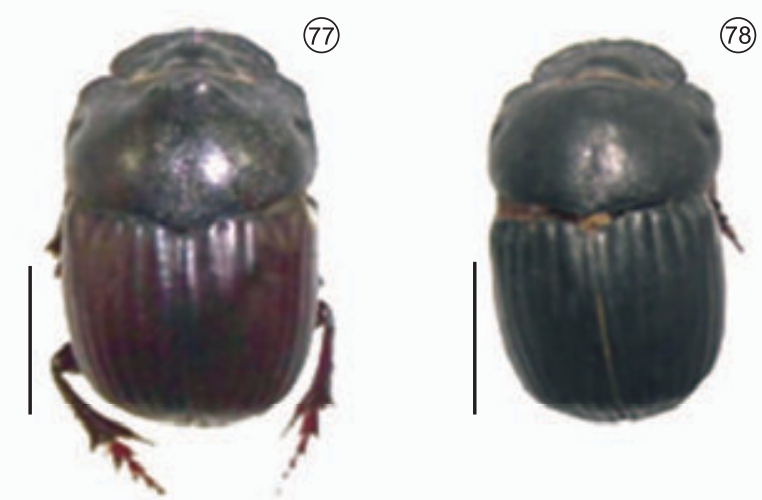

Figuras 73-78. 73, 74) Dichotomius nisus (macho e fêmea); 75) Ontherus sulcator; 76) Ontherus azteca; 77, 78) Homocopris sp. (macho e fêmea). Escalas: $0,5 \mathrm{~cm}$.

Figures 73-78. 73, 74) Dichotomius nisus (male and female); 75) Ontherus sulcator; 76) Ontherus azteca; 77, 78) Homocopris sp. (male and female). Scales: $0.5 \mathrm{~cm}$.

\section{Dichotomius assifer}

Espécie de floresta e hábito alimentar coprófago; pode ser capturada em armadilhas iscadas com carne e fruta apodrecida, mas em número reduzido. Distribui-se pelo sul e sudeste do Brasil; é atraída também por luz artificial (Luederwaldt 1929). Frequente ao longo de todo o ano.

\section{Dichotomius nisus}

Espécie coprófaga, também atraída por luz artificial (Luederwaldt 1929, Martínez 1959, Link 1976); possui ampla distribuição pela região Neotropical (Luederwaldt 1929, Martínez 1959). Ocorre principalmente em ecossistemas abertos no período de temperaturas mais elevadas; indivíduos foram capturados em armadilhas iscadas com carne e fruta apodrecida.

\section{Homocopris sp.}

Gênero recentemente revalidado (Vaz-de-Mello et al. 2010) e em processo de revisão; possui espécies chilenas e brasileiras, as últimas, relacionadas a fragmentos de Floresta Atlântica distribuídos pelo sul e sudeste do Brasil (Vaz-de-Mello et al. 2008). Os dois exemplares capturados foram atraídos à armadilha de fezes humanas em ecossistema florestal montanhoso preservado, em maio e outubro de 2009.

\section{Ontherus appendiculatus}

Com ampla distribuição pela América do Sul, é atraída por fezes bovinas, humanas e por armadilhas luminosas, tanto em florestas como áreas abertas durante todo o ano (Génier 1996).

\section{Ontherus azteca}

Espécie encontrada em armadilhas iscadas com fezes humanas e carne apodrecida em áreas florestais da costa atlântica brasileira e da costa pacífica da América do Sul e Central (Génier 1996). Indivíduos foram registrados principalmente durante a primavera e verão.

\section{Ontherus sulcator}

Comum e de ampla distribuição pela região Neotropical, é encontrada principalmente em excrementos de herbívoros e fezes humanas (Martínez 1959); pode ser atraída por carcaça e luz artificial (Link 1976, Génier 1996). Foi registrada principalmente em isca de fezes humanas, mas ocorreu também em armadilhas com carne e fruta apodrecida; é frequente ao logo de todo o ano.

\section{DELTOCHILINI}

\section{Canthon amabilis}

Espécie de floresta e de hábito alimentar generalista, com tendência à necrofagia. Capturada principalmente na primavera e verão. Distribui-se pelo sul do Brasil, de onde foi descrita (estado de Santa Catarina) (Balthasar 1939).

\section{Canthon chalybaeus}

Encontrada em cadáveres de animais mortos, desde estágios recentes a avançados de decomposição, e também em excre- 
mentos nos primeiros momentos de deposição (Luederwaldt 1911, Martínez 1959, 1987); possui ampla distribuição pela América do Sul. Capturada durante todo o ano, com pouca atividade durante o inverno, em maiores números em armadilhas iscadas com carne apodrecida. Entretanto, em ecossistemas mais degradados, apresentou grande atração à isca de fezes humanas e fruta apodrecida.

\section{Canthon latipes}

Encontrada em excrementos de herbívoros e de humanos (Martínez 1959) e em frutos maduros de butiá (Pereira \& Martínez 1956). Foi também atraída à isca de carne apodrecida; indivíduos foram capturados em todas as estações, exceto no inverno. Distribui-se pelo sul e sudeste do Brasil, Argentina e Uruguai, em ecossistemas florestais montanhosos (Vulcano \& Pereira 1964, Martínez 1987).

\section{Canthon lividus}

Possui hábito alimentar generalista (Martínez 1959, Halffter \& Matthews 1966), mas também é atraída por luz artificial (Link 1976); se distribui pelo Brasil, Argentina, Paraguai e Uruguai (Martínez 1959). Registrada ao longo de todo o ano, com menores números no inverno.

\section{Canthon aff. luctuosus}

Espécie generalista, capturada em fezes humanas, carne e fruta apodrecidas. Ocorre ao longo de todo o ano, com decréscimo de abundância no inverno.

\section{Canthon oliverioi}

Encontrada em excrementos (Pereira \& Martínez 1956), mas também capturada com iscas de carne apodrecida. Distribui-se pelo sul e sudeste do Brasil, Argentina e Uruguai (Martínez 1959, Vulcano \& Pereira 1964). Ocorre durante a primavera e verão.

\section{Canthon quinquemaculatus}

Com ampla distribuição na região Neotropical, é frequente em cadáveres de animais em estágios iniciais de decomposição (Martínez 1959, Halffter \& Matthews 1966). Há registro de coleta em cortes recentes de liana, atraída pelo odor fétido desprendido da mesma (Pereira \& Martínez 1956), embora Martínez (1987) a cite como exclusivamente necrófaga. Foi capturada mais abundantemente em armadilhas iscadas com carne apodrecida, mas esteve presente também às iscadas com fezes humanas e fruta apodrecida. Aparentemente se adapta bem a ambientes perturbados.

\section{Deltochilum brasiliense}

Espécie generalista (Almeida \& Louzada 2009) que se distribui pelo centro-sul do Brasil, Argentina e Colômbia (Vulcano \& Pereira 1964). Registrada em ecossistemas florestais, ocorre durante quase todo o ano.

\section{Deltochilum morbillosum}

Foi coletada em armadilha de queda iscada com carne apodrecida e excremento humano, durante a primavera e verão. Distribui-se em ecossistemas florestais do sul e sudeste do Brasil (Vulcano \& Pereira 1964).

\section{Deltochilum rubripenne}

Encontrada em excrementos humanos, de herbívoros (Martínez 1959) e em armadilhas iscadas com carne apodrecida e banana fermentada, durante a primavera e verão. Distribui-se pelo centro-sul do Brasil, Argentina e Paraguai (Martínez 1959, Vulcano \& Pereira 1964).

\section{Deltochilum sculpturatum}

Espécie necrófaga que se distribui pelo sudeste e sul do Brasil e na Argentina (Martínez 1959), onde é frequente em ecossistemas campestres. Atraída também às iscas de fezes humanas e fruta apodrecida.

\section{ONITICELLINI}

\section{Eurysternus aeneus}

Distribui-se pelo sul e sudeste do Brasil, Argentina e Paraguai (Génier 2009), tanto em áreas florestais como campestres; possui aparentemente hábito alimentar coprófago. O exemplar capturado ocorreu no mês de dezembro em fragmento florestal perturbado.

\section{Eurysternus caribaeus}

Espécie coprófaga, amplamente distribuída pela região Neotropical (Génier 2009). Foi capturada atraída por fruta e carne apodrecida e em maior número por fezes humanas; é frequente durante o ano todo.

\section{Eurysternus parallelus}

Espécie coprófaga, muito atraída por excremento humano fresco; se distribui pelo sudeste e sul do Brasil, Argentina e Paraguai (Martínez 1959, Génier 2009). Foi capturada em menor número com isca de carne e fruta apodrecida; possui frequência reduzida no inverno.

\section{ONTHOPHAGINI}

\section{Onthophagus catharinensis}

Espécie coprófaga que pode também ocorrer em armadilhas iscadas com fruta e carne apodrecida. Ocorre em ecossistemas florestais preservados e é pouco frequente no inverno em Santa Maria. Distribui-se também em Santa Catarina, de onde provém o material do qual foi descrita (Paulian 1936).

\section{Onthophagus aff. tristis}

Espécie coprófaga; pode ocorrer, em menor número, em armadilhas com carne e fruta apodrecida. Frequente durante todo o ano em Santa Maria.

\section{PHANAEINI}

\section{Coprophanaeus milon}

Espécie necrófaga que utiliza pequenos mamíferos ou aves mortas para a preparação de sua bola-ninho e alimentação do adulto; pode ser atraída por luz artificial (Martínez 1959, Halffter \& Matthews 1966) e, em menor número, por armadilhas com fezes humanas (Silva et al. 2009). Distribui-se pelo sudeste e sul do Brasil e também no Mato Grosso do Sul, Argentina, Paraguai e Uruguai (Martínez 1959, Arnaud 2002, Edmonds \& Zídek 2010); é frequente em ecossistemas campestres. Em Santa Maria, ocorreu apenas na primavera e verão.

\section{Coprophanaeus saphirinus}

Martínez (1959) afirma ser uma espécie coprófaga, encontrada principalmente em excrementos de herbívoros. Em Santa Maria, foi encontrada em maior número atraída por carne apodrecida; em menor número, foi atraída por fezes humanas e poucos indivíduos capturados com fruta apodrecida. É frequente nos meses de primavera e verão, em ecossistemas flo- 
restais. Ocorre no sudeste e sul do Brasil e também na Bahia, Argentina e Paraguai (Martínez 1959, Arnaud 2002, Edmonds \& Zídek 2010); possui variação de coloração entre populações de diferentes localidades (Edmonds \& Zídek 2010).

\section{Phanaeus splendidulus}

Espécie coprófaga que se distribui pela costa atlântica brasileira, da Bahia até a região sul, e pela Argentina (Edmonds 1994). Pode ser capturada em armadilha com carne apodrecida. Em Santa Maria, ocorreu em ecossistemas florestais preservados, principalmente durante a primavera e alguns poucos indivíduos no verão.

\section{Sulcophanaeus rhadamanthus}

Distribui-se pela Floresta Atlântica do sudeste e sul do Brasil, talvez se alimentando de fungos e vivendo em ninhos de insetos sociais ou tocas de pequenos vertebrados (Edmonds 2000). Em Santa Maria, foi registrada em armadilhas iscadas com fezes humanas no mês de maio, e também em armadilha de interceptação de voo no mês de julho, em fragmento de floresta preservada montanhosa.

\section{Agradecimentos}

Ao IBAMA pela concessão de licença para coleta; a Capes pela bolsa de estudos ao primeiro autor. Este trabalho contou com auxílios parciais da FAPEMAT (570847/2008 e 447441/2009) e CNPq (151603/2007-3 e 304925/2010-1).

\section{Referências Bibliográficas}

ALMEIDA, L.M., COSTA, C.S.R. \& MARINONI, L. 1998. Manual de coleta, conservação, montagem e identificação de insetos. Holos, Ribeirão Preto.

ALMEIDA, S.S.P. \& LOUZADA, J.N.C. 2009. Estrutura da comunidade de Scarabaeinae (Scarabaeidae: Coleoptera) em fitofisionomias do Cerrado e sua importância para a conservação. Neotrop. Entomol. 38(1):32-43. http://dx.doi.org/10.1590/S1519-566X2009000100003

ARNAUD, P. 2002. Les Coléoptères du Monde, Phanaeini. vol. 28. Hillside Books, Canterbury.

AUDINO, L.D. 2007. Resposta da comunidade de Scarabaeidae a degradação e substituição de área de campo nativo por pastagem cultivada na região da Campanha, município de Bagé, RS. Monografia de Conclusão de Curso de Ciências Biológicas, Universidade da Região da Campanha, Bagé.

AUDINO, L.D., SILVA, P.G., NOGUEIRA, J.M., MORAES, L.P. \& VAZDE-MELLO, F.Z. 2011. Scarabaeinae (Coleoptera, Scarabaeidae) de um bosque de eucalipto introduzido em uma região orginalmente campestre. Iheringia. Sér. Zool. 101(1-2):121-126.

BALTHASAR, V. 1939. Eine Vorstudie zur Monographie der Gattung Canthon Hffsg. (10. Beitrag zur Kenntnis der Scarababaeiden der neotropischen Region). Folia Zool. Hydrob. 9(2):179-238.

BANG, H.S., LEE, J.H., KWON, O.S., NA, Y.E., JANG, Y.S. \& KIM, W.H. 2005. Effects of paracoprid dung beetles (Coleoptera: Scarabaeidae) on the growth of pasture herbage and on the underlying soil. Appl. Soil Ecol. 29:165-171. http://dx.doi.org/10.1016/j.apsoil.2004.11.001

BORROR, D.J., TRIPLEHORN, C.A. \& JOHNSON, N.F. 1992. An introduction to the study of insects. 6nd ed. Harcout Brace \& Cia, Orlando.

BROWNE, J. \& SCHOLTZ, C.H. 1999. A phylogeny of the families of Scarabaeoidea (Coleoptera). Syst. Entomol. 24:51-84. http://dx.doi. org/10.1046/j.1365-3113.1999.00067.x

CAMBEFORT, Y. \& HANSKI, I. 1991. Dung beetle population biology. In Dung beetle ecology (I. Hanski \& Y. Cambefort, eds.). Princeton University Press, Princeton, USA.

CAMBEFORT, Y. 1991. Biogeography and evolution. In Dung beetle ecology (I. Hanski \& Y. Cambefort, eds.). Princeton University Press, Princeton, USA.
COOK, J. 1998. A revision of the Neotropical genus Bdelyrus Harold (Coleoptera: Scarabaeidae). Can. Entomol. 130:631-689. http://dx.doi. org/10.4039/Ent130631-5

COSTA, C.M.Q., SILVA, F.A.B., FARIAS, A.I. \& MOURA, R.C. 2009. Diversidade de Scarabaeinae (Coleoptera, Scarabaeidae) coletados com armadilha de interceptação de vôo no Refúgio Ecológico Charles Darwin, Igarassu-PE, Brasil. Rev. Bras. Entomol. 53(1):88-94. http://dx.doi. org/10.1590/S0085-56262009000100021

DAVIS, A.L.V., SCHOLTZ, C.H. \& PHILIPS, T.K. 2002. Historical biogeography of scarabaeine dung beetles. J. Biogeogr. 29:1217-1256.

DAVIS, A.L., SCHOLTZ, C.H., DOOLEY, P., BHAM, N. \& KRYGER, U. 2004. Scarabaeine dung beetles as indicators of biodiversity, habitat transformation and pest control chemicals in agro-ecosystems. S. Afr. J. Sci. 100:415-424. http://dx.doi.org/10.1046/j.1365-2699.2002.00776.x

EDMONDS, W.D. \& ZÍDEK, J. 2010. A taxonomic review of the genus Coprophanaeus Olsoufieff, 1924 (Coleoptera: Scarabaeidae: Scarabaeinae). Insecta Mundi 129:1-111.

EDMONDS, W.D. 1994. Revision of Phanaeus Macleay, a new world genus of Scarabaeinae dung beetles (Coleoptera: Scarabaeidae, Scarabaeinae). Contrib. Sci. 443:1-105.

EDMONDS, W.D. 2000. Revision of the Neotropical dung beetle genus Sulcophanaeus (Coleoptera: Scarabaeidae: Scarabaeinae). Fol. Heyrovsk., Suppl. 6:1-60.

EMLEN, D.J. 2008. The evolution of animal weapons. Annu. Rev. Ecol. Evol. Syst. 39:387-413. http://dx.doi.org/10.1146/annurev. ecolsys.39.110707.173502

FALQUETO, S.A., VAZ-DE-MELLO, F.Z. \& SCHOEREDER, J.H. 2005. Are fungivorous Scarabaeidae less specialist? Ecol. Austral 15:17-22.

FAVILA, M.E. \& HALFFTER, G. 1997. The use of indicator groups for measuring biodiversity as related to community structure and function. Acta Zool. Mex. 72:1-25.

GÉNIER, F. 1996. A revision of the Neotropical genus Ontherus Erichson (Coleoptera, Scarabaeidae, Scarabaeinae). Mem. Entomol. Soc. Can. 170:1-169. http://dx.doi.org/10.4039/entm128170fv

GÉNIER, F. 2009. Le genre Eurysternus Dalman, 1824 (Scarabaeidae: Scarabaeinae: Oniticellini), revision taxonomique et clés de determination illustrées. Sofia, Pensoft.

GILL, B.D. 1991. Dung beetle in Tropical American Forest. In Dung beetle ecology (I. Hanski \& Y. Cambefort, eds.). Princeton University Press, Princeton.

GONZÁLEZ-VAINER, P. \& MORELLI, E. 2008. Relevamiento de los coleópteros coprofilos y necrófilos de Sierra de Minas, Uruguay (Insecta: Coleoptera). Bol. Soc. Zool. Uruguay 17:20-33.

HALFFTER, G. \& EDMONDS, W.D. 1982. The nesting behavior of dung beetles (Scarabaeinae): An ecologic and evolutive approach. Man and Biosphere Program UNESCO, México.

HALFFTER, G. \& FAVILA, M.E. 1993. The Scarabaeidae (Insecta: Coleoptera) an animal group for analyzing, inventorying and monitoring biodiversity in tropical rainforest and modified landscapes. Biol. Int. 27:15-21.

HALFFTER, G. \& MATTHEWS, E.G. 1966. The natural history of dung beetles of the subfamily Scarabaeinae (Coleoptera: Scarabaeidae). Fol. Entomol. Mex. 12-14:1-312.

HALFFTER, G. 1977. Evolution of nidification in the Scarabaeinae (Coleoptera: Scarabaeidae). Quaest. Entomol. 13:231-352.

HALFFTER, G. 1991. Historical and ecological factors determining the geographical distribution of beetles (Coleoptera: Scarabaeidae: Scarabaeinae). Fol. Entomol. Mex. 82:195-238.

HANSKI, I. \& CAMBEFORT, Y. 1991. Competition in dung beetles. In Dung beetle ecology (I. Hanski \& Y. Cambefort, eds.). Princeton University Press, Princeton.

HERNÁNDEZ, M.I.M. 2002. The night and day of dung beetles (Coleoptera, Scarabaeidae) in the Serra do Japi, Brazil: elytra colour related to daily activity. Rev. Bras. Entomol. 46(4):597-600. http://dx.doi.org/10.1590/ S0085-56262002000400015 
HERNÁNDEZ, M.I.M., MONTEIRO, L.R. \& FAVILA, M.E. 2011. The role of body size and shape in understanding competitive interactions within a community of Neotropical dung beetles. J. Insect Sci. 11(13):1-14. PMid:21526928. http://dx.doi.org/10.1673/031.011.0113

HERRERA, E.R.T., VULINEC, K., KNOGGE, C. \& HEYMANN, W.E. 2002. Sit and wait at the source of dung - an unusual strategy of dung beetles. Ecotropica 8:87-88.

HONER, M. R., BIANCHIN, I. \& GOMES, A. 1992. Com besouros africano, controle rápido e eficiente. In Manual de Controle Biológico. Sociedade Nacional de Agricultura / Andina / Sondotécnica, Rio de Janeiro, Brasil.

JACOBS, J., NOLE, I., PALMINTERI, S. \& RATCLIFFE, B. 2008. First come, first serve: "Sit and wait" behavior in dung beetles at the source of primate dung. Neotrop. Entomol. 37(6):641-645. PMid:19169550. http://dx.doi.org/10.1590/S1519-566X2008000600003

KOHLMANN, B. 2006. History of Scarabaeoid classification. Coleopt. Soc. Monogr. N. 5:19-34.

KOLLER, W.W., GOMES, A. \& RODRIGUES, S.R. 2006. Perspectivas de degradação de fezes bovinas pelo besouro coprófago africano, Digitonthophagus gazella, e espécies sul-americanas (Coleoptera, Scarabaeidae e Aphodiidae). Embrapa-CNPGC, Campo Grande.

KOLLER, W.W., GOMES, A., RODRIGUES, S.R. \& GOIOZO, P.F.I. 2007. Scarabaeidae e Aphodiidae coprófagos em pastagens cultivadas em área do cerrado sul-mato-grossense. Rev. Bras. Zooc. 9(1):81-93.

LAWRENCE, J.F. \& BRITTON, E.B. 1994. Australian Beetles. Melbourne University Press, Melbourne, Australia.

LAWRENCE, J.F. \& NEWTON, A.F. 1995. Families and subfamilies of Coleoptera (with selected genera, notes, references and data on familygroup names). In Biology, Phylogeny and Classification of Coleoptera. Papers celebrating the 80th birthday of Roy A. Crowson (J. Pakaluk \& S. A. Slipinski, eds.). Muzeum i Instytut Zoologii PAN, Warszawa, Poland.

LINK, D. 1976. Abundância relativa e fenologia de alguns Scarabaeoidea fototáticos, na zona de campos de Santa Maria, RS. (Coleoptera). Tese de Doutorado, Universidade Federal do Paraná, Curitiba.

LOBO, J.M., MARTÍN-PIERA, F. \& VEIGA, C.M. 1988. Las trampas pitfall con sebo, sus posibilidades en el estudio de las comunidades coprófagas de Scarabaeoidea (Col.). I. Características determinantes de su capacidad de captura. Rev. Ecol. Biol. Sol 25(1):77-100.

LOUZADA, J.N.C. \& SILVA, P.R.C. 2009. Utilisation of introduced Brazilian pastures ecosystems by native dung beetles: diversity patterns and resource use. Insect Conserv. Divers. 2:45-52. http://dx.doi.org/10.1111/ j.1752-4598.2008.00038.x

LOUZADA, J.N.C. \& VAZ-DE-MELLO, F.Z. 1997. Scarabaeidae (Coleoptera, Scarabaeoidea) atraídos por ovos em decomposição em Viçosa, Minas Gerais, Brasil. Caldasia 19(3):521-522.

LUEDERWALDT, H. 1911. Os insectos necrófagos Paulistas. Rev. Mus. Paulista 8:414-433.

LUEDERWALDT, H. 1929. As espécies brasileiras do gênero Pinotus. (Coleoptera - Lamellicornidae - Coprini), com algumas considerações também sobre outras espécies. Rev. Mus. Paulista 16:1-173.

MARTÍNEZ, A. \& HALFFTER, G. 1986. Situación del genero Canthidium Erichson (Coleoptera: Scarabaeidae: Scarabaeinae). Acta Zool. Mex. 17:19-40.

MARTÍNEZ, A. 1959. Catalogo de los Scarabaeidae Argentinos (Coleoptera). Rev. Mus. Arg. Cienc. Nat. 5:1-126.

MARTÍNEZ, A. 1987. La entomofauna de Scarabaeinae de la provincia de Salta (Col. Scarabaeoidea). An. Soc. Cient. Arg. 216:45-69.

MATTHEWS, E.G. 1972. A revision of the scarabaeine dung beetles of Australia. I. Tribe Onthophagini. Aust. J. Zool. Suppl. Ser. 9:1-133.

MILHOMEM, M.S., VAZ-DE-MELLO, F.Z. \& DINIZ, I.R. 2003. Técnicas de coleta de besouros copronecrófagos no Cerrado. Pesq. Agropec. Bras. 38(11):1249-1256.
MIRANDA, C.H.B., NASCIMENTO, Y.A. \& BIANCHIN, A. 1990. Desenvolvimento de um programa entregado de controle dos nematódeos e a mosca-dos-chifres na região dos cerrados. Fase 3. Potencial de Onthophagus gazella no enterrio de fezes bovinas. Embrapa-CNPGC, Campo Grande, Brasil

MONAGHAN, M.T., INWARD, D.J.G., HUNT, T. \& VOGLER, A.P. 2007. A molecular phylogenetic analysis of the Scarabaeinae (dung beetles). Mol. Phylog. Evol. 45:674-692. PMid:17656114. http://dx.doi.org/10.1016/j. ympev.2007.06.009

NAVARRETE-HEREDIA, J.L. \& GALINDO-MIRANDA, N.E. 1997. Escarabajos associados a Basidiomycetes en San Jose de los Laurelles, Morelos, Mexico (Coleoptera: Scarabaeidae). Fol. Entomol. Mex. 99:1-16.

NICHOLS, E., SPECTOR, S., LOUZADA, J., LARSEN, T., AMEZQUITA, S. \& FAVILA, M.E. 2008. Ecological functions and ecosystem services provided by Scarabaeinae dung beetles. Biol. Conser. 141:1461-1474. http://dx.doi.org/10.1016/j.biocon.2008.04.011

OCAMPO, F.C. \& HAWKS, D.C. 2006. Molecular phylogenetics and evolution of the food relocation behavior of the dung beetle tribe Eucraniini (Coleoptera, Scarabaeidae, Scarabaeinae). Invert. Syst. 20:557570. http://dx.doi.org/10.1071/IS05031

PAULIAN, R. 1936. Sur quelques Onthophagus américains nouveaux ou peu connus (Col. Lamellicornes). Festsch. 60 Gehurt. Prof. Embrik Strand 1:506-509.

PEREIRA, F.S. \& MARTÍNEZ, A. 1956. Os gêneros de Canthonini americanos (Col. Scarabaeidae). Rev. Bras. Entomol. 6:91-192.

PESSÔA, S.B. \& LANE, F. 1941. Coleópteros necrófagos de interêsse médicolegal. Ensaio monográfico sôbre a família Scarabaeidae de S. Paulo e regiões vizinhas. Arq. Zool. Est. S. Paulo 2:389-504.

PFROMMER, A. \& KRELL, F.T. 2004. Who steals the eggs? Coprophanaeus telamon (Erichson) buries decomposing eggs in western Amazonian rain forest (Coleoptera: Scarabaeidae). Coleopt. Bull. 58(1):21-27. http:// dx.doi.org/10.1649/585

PHILIPS, T.K., PRETORIUS, E. \& SCHOLTZ, C.H. 2004. A phylogenetic analysis of dung beetles (Scarabaeinae: Scarabaeidae): unrolling an evolutionary history. Invert. Syst. 18:53-88. http://dx.doi.org/10.1071/ IS03030

RATCLIFFE, B.C. \& JAMESON, M.L. 2004. The revised classification for Scarabaeoidea: What the Hell is going on? Scarabs 15:3-10.

RATCLIFFE, B.C. \& SMITH, A.B.T. 1999. New species of Canthonella Chapin (Scarabaeidae: Scarabaeinae) from Amazonian Brazil. Coleopt. Bull. 53(1):1-7.

RIDSDILL-SMITH, T.J. \& HAYLES, L. 1990. Stages of bush fly, Musca vetustissima (Diptera: Muscidae), killed by Scarabaeinae dung beetles (Coleoptera: Scarabaeidae) in unfavourable cattle dung. Bull. Entomol. Res. 80:473-478. http://dx.doi.org/10.1017/S0007485300050744

RONQUI, D.C. \& LOPES, J. 2006. Composição e diversidade de Scarabaeoidea (Coleoptera) atraídos por armadilha de luz em área rural no norte do Paraná, Brasil. Iheringia, Sér. Zool. 96(1):103-108.

ROUGON, C. \& ROUGON, D. 1980. Contribuition à la Biologie des Coléopteres coprophages en region sahélienne. Ètude du développement d`Onthophagus gazella (Coleoptera: Scarabaeidae). Rev. Ecol. Biol. Sol 17(3):379-339.

SCHOOLMEESTERS, P., DAVIS, A.L.V., EDMONDS, W.D., GILL, B., MANN, D., MORETTO, P., PRICE, D., REID, C., SPECTOR, S. \& VAZ-DE-MELLO, F.Z. 2010. ScarabNet Global Taxon Database (version 1.5). http://216.73.243.70/scarabnet/results.htm (último acesso em 16/08/2010).

SILVA, P.G. \& VIDAL, M.B. 2007. Atuação dos escarabeídeos fimícolas (Coleoptera: Scarabaeidae sensu stricto) em áreas de pecuária: potencial benéfico para o município de Bagé, Rio Grande do Sul, Brasil. Rev. Ciênc. Agrovet. 6(2):162-169.

SILVA, P.G. 2011. Dung beetles (Coleoptera: Scarabaeidae: Scarabaeinae) of two non-native habitats in Bagé, Rio Grande do Sul, Brazil. Zool. Stud. 50(5):546-559.

SILVA, P.G., GARCIA, M.A.R. \& VIDAL, M.B. 2008. Besouros copronecrófagos (Coleoptera: Scarabaeidae stricto sensu) coletados em ecótono natural de campo e mata em Bagé, RS. Ciência e Natura 30(2):71-91. 
SILVA, P.G., GARCIA, M.A.R. \& VIDAL, M.B. 2009. Besouros copronecrófagos (Coleoptera: Scarabaeidae sensu stricto) do município de Bagé, RS (Bioma Campos Sulinos). Biociências 17(1):33-43.

SILVA, P.G., GARCIA, M.A.R., AUDINO, L.D., NOGUEIRA, J.M., MORAES, L.P., RAMOS, A.H.B., VIDAL, M.B. \& BORBA, M.F.S. 2007. Besouros rola-bosta: insetos benéficos das pastagens. Rev. Bras. Agroecol. 2:1428-1432.

SPECTOR, S. 2006. Scarabaeine dung beetles (Coleoptera: Scarabaeidae: Scarabaeinae): an invertebrate focal taxon for biodiversity research and conservation. Coleopt. Bull. 5:71-83. http://dx.doi.org/10.1649/0010065X(2006)60[71:SDBCSS]2.0.CO;2

VAZ-DE-MELLO, F.Z. 2000. Estado de conhecimento dos Scarabaeidae s. str. (Coleoptera: Scarabaeoidea) do Brasil. In Hacia un proyecto CYTED para el inventario y estimación de la diversidad entomológica en Iberoamérica (F. Martín-Piera, J.J. Morrone \& A. Melic, eds.). Sociedad Entomológica Aragonesa, Zaragoza, Spain.

VAZ-DE-MELLO, F.Z. 2007a. Revision and phylogeny of the dung beetle genus Zonocopris Arrow 1932 (Coleoptera: Scarabaeidae: Scarabaeinae), a phoretic of land snails. Ann. Soc. Entomol. Fr. 43(2):231-239.

VAZ-DE-MELLO, F.Z. 2007b. Revisión taxonômica y análisis filogenético de la tribu Ateuchini (Coleoptera: Scarabaeidae: Scarabaeinae). Tese de Doutorado, Instituto de Ecología, Xalapa.

VAZ-DE-MELLO, F.Z. 2008. Synopsis of the new subtribe Scatimina (Coleoptera: Scarabaeidae: Scarabaeinae: Ateuchini), with descriptions of twelve new genera and review of Genieridium, new genus. Zootaxa 1955:1-75.
VAZ-DE-MELLO, F.Z., EDMONDS, W.D., OCAMPO, F. \& SCHOOLMEESTERS, P. 2011. A multilingual key to the genera and subgenera of the subfamily Scarabaeinae of the New World. Zootaxa. Zootaxa 2854:1-73.

VAZ-DE-MELLO, F.Z., GÉNIER, F. \& SMITH, A.B.T. 2008. Novo status e revisão taxonômica do gênero Homocopris Burmeister (Insecta, Coleoptera, Scarabaeidae, Scarabaeinae, Coprini). In Congresso Brasileiro de Zoologia. Sociedade Brasileira de Zoologia, Curitiba.

VAZ-DE-MELLO, F.Z., GÉNIER, F. \& SMITH, S.B.T. 2010. Reclassification of Homocopris Burmeister as a valid genus to accomodate three species formerly in Dichotomius Hope (Scarabaeidae: Scarabaeinae: Coprini). Coleopt. Bull. 64(3):192-192. http://dx.doi.org/10.1649/0010065X-64.3.192.3

VAZ-DE-MELLO, F.Z., LOUZADA, J.N.C. \& SCHOEREDER, J.H. 1998. New data and comments on Scarabaeidae (Coleoptera: Scarabaeoidea) associated with Attini (Hymenoptera: Formicidae). Coleopt. Bull. 52(3):209-216.

VULCANO, M.A. \& PEREIRA, F.S. 1964. Catalogue of the Canthonini (Col. Scarab.) inhabiting the Western Hemisphere. Entomol. Arb. Mus. G. Frey 15:570-685.

VULINEC, K. 1997. Iridescent dung beetles: a different angle. Fla. Entomol. 80:132-141. http://dx.doi.org/10.2307/3495550

YOUNG, O.P. 1984. Perching of Neotropical dung beetles on leaf surfaces: An example of behavioural termoregulation? Biotropica 16:324-327. http://dx.doi.org/10.2307/2387944

Recebido em 18/04/2011 Versão reformulada recebida em 23/12/2011 Publicado em 28/12/2011 
